UCRL-TR-218932

\title{
Single Molecule Studies of Chromatin
}

C. Jeans, M. P. Thelen, A. Noy

\section{$13^{\text {th }}$ February 2006}




\section{Disclaimer}

This document was prepared as an account of work sponsored by an agency of the United States Government. Neither the United States Government nor the University of California nor any of their employees, makes any warranty, express or implied, or assumes any legal liability or responsibility for the accuracy, completeness, or usefulness of any information, apparatus, product, or process disclosed, or represents that its use would not infringe privately owned rights. Reference herein to any specific commercial product, process, or service by trade name, trademark, manufacturer, or otherwise, does not necessarily constitute or imply its endorsement, recommendation, or favoring by the United States Government or the University of California. The views and opinions of authors expressed herein do not necessarily state or reflect those of the United States Government or the University of California, and shall not be used for advertising or product endorsement purposes.

\section{Auspices Statement}

This work was performed under the auspices of the U. S. Department of Energy (DOE) by the University of California, Lawrence Livermore National Laboratory (LLNL) under Contract No. W-7405-Eng-48. The project (03-ERI-011) was funded by the Laboratory Directed Research and Development Program at LLNL. 


\title{
FY05 LDRD Final Report Single Molecule Studies of Chromatin LDRD Project Tracking Code: 03-ERI-011
}

\begin{abstract}
In eukaryotic cells, DNA is packaged as chromatin, a highly ordered structure formed through the wrapping of the DNA around histone proteins, and further packed through interactions with a number of other proteins. In order for processes such as DNA replication, DNA repair, and transcription to occur, the structure of chromatin must be remodeled such that the necessary enzymes can access the DNA. A number of remodeling enzymes have been described, but our understanding of the remodeling process is hindered by a lack of knowledge of the fine structure of chromatin, and how this structure is modulated in the living cell. We have carried out single molecule experiments using atomic force microscopy (AFM) to study the packaging arrangements in chromatin from a variety of cell types. Comparison of the structures observed reveals differences which can be explained in terms of the cell type and its transcriptional activity. During the course of this project, sample preparation and AFM techniques were developed and optimized. Several opportunities for follow-up work are outlined which could provide further insight into the dynamic structural rearrangements of chromatin.
\end{abstract}




\section{Introduction}

DNA is packaged as chromatin in the chromosomes of eukaryotic cells through association with numerous proteins. The best understood unit of packing is the nucleosome, a core octamer of histone proteins with 1.7 turns of DNA wrapped around it. The X-ray crystal structure of the mononucleosome has been solved (Luger et al., 1997) and is shown in Figure 1a. Nucleosomes themselves are organized into $30 \mathrm{~nm}$ fibers, which are then organized into higher order structures (Alberts et al., 2002). Figure 1b shows this general arrangement. It has long been known that condensed chromatin (heterochromatin) is transcriptionally silent compared to the less condensed chromatin (euchromatin). However, the precise structural differences between euchromatin and heterochromatin are far from clear. The complex packaging of chromatin makes the DNA double helix inaccessible to external proteins. This means that for processes such as DNA replication, repair, and recombination to occur, some degree of remodeling of the chromatin structure is required. Remodeling has wider reaching effects: it is involved in gene activation and silencing (Grewal and Elgin, 2002), it has been linked to a number of cancers (Neely and Workman, 2002) and is likely to be of importance in the maintenance of telomeres (Shore, 2001).

The precise nature of the remodeling process is not fully understood, although a number of remodeling enzymes have been described. Broadly speaking, these fall into two classes: histone acetyltransferases and ATP-dependent remodeling enzymes (Peterson and Workman, 2000; Pollard and Peterson, 1998; Vignali et al., 2000). Histone acetylation can be seen as a paradigm for chromatin remodeling. Although the precise effects of histone acetylation on chromatin structure are not known, the main effect appears to be at the level of inter-nucleosomal interactions rather than at the level of individual nucleosome structure. Acetylation of nucleosomes implies transcriptional activation, and may serve as a molecular marker for other remodeling systems. Other modifications of histones such as methylation and phosphorylation are also known to occur (Fischle et al., 2003; Strahl and Allis, 2000). 
Although several structures of remodeled chromatin have been proposed, they all suffer from a lack of experimental validation. Remodeling seems to primarily affect the interactions between nucleosomes. Our approach used imaging techniques which allowed the study of biological samples under near in vivo conditions. Samples of chromatin from chicken erythrocytes (CE) and Chinese hamster ovary (CHO) cells were studied. Chicken erythrocyte chromatin is heavily compacted and silenced, CHO cell chromatin is transcriptionally active. $\mathrm{CHO}$ cells were also grown in the presence of sodium butyrate, a chemical known to force chromatin remodeling through inhibition of histone deacetylases (D'Anna et al., 1980). These three samples form a spectrum of chromatin types from silenced, through normal to forcibly remodeled. 


\title{
Materials and Methods
}

\author{
Sample preparation.
}

\section{Chicken erythrocyte chromatin preparation.}

Chicken erythrocyte (CE) chromatin was prepared according to a published procedure (Yager et al., 1989), with some modifications. Whole chicken blood (with heparin) was purchased from Pel-Freeze (Location). Blood was filtered through muslin, then erythrocytes were pelleted at $2000 \mathrm{~g}$ for 4 mins. The cell pellet was washed in 25 volumes of buffer A ( $0.34 \mathrm{M}$ sucrose, $15 \mathrm{mM}$ Tris $\mathrm{pH}$ 7.5, $60 \mathrm{mM} \mathrm{KCl}, 15 \mathrm{mM} \mathrm{NaCl}, 0.5$ $\mathrm{mM}$ spermidine, $0.15 \mathrm{mM}$ spermine, $2 \mathrm{mM}$ EDTA, $2 \mathrm{mM}$ EGTA, $15 \mathrm{mM} \beta$ mercaptoethanol, $0.1 \mathrm{mM}$ PMSF). Cells were pelleted again and resuspended in buffer A $+0.5 \%$ NP-40 (lysis buffer) and homogenized. Nuclei were pelleted at $1000 \mathrm{~g}$ for 5 mins and washed twice in lysis buffer. Nuclei were resuspended by trituration into lysis buffer to a DNA concentration of about $3 \mathrm{mg} / \mathrm{ml}$. DNA concentration was measured by $\mathrm{A}_{260}$ in $0.1 \mathrm{M} \mathrm{NaOH}$ : a $1 \mathrm{mg} / \mathrm{ml}$ DNA solution having $\mathrm{A}_{260}=20$. Since the mass of histone protein in a sample of chromatin is roughly the same as that of the DNA, the DNA concentration of a sample is roughly equal to the protein concentration. In this report, the concentration of sample is always given as $\mathrm{mg} \mathrm{DNA} / \mathrm{ml}$.

To fragment chromatin, nuclei were washed into buffer B (0.34 M sucrose, $15 \mathrm{mM}$ Tris pH 7.5, $60 \mathrm{mM} \mathrm{KCl,} 15 \mathrm{mM} \mathrm{NaCl}, 0.5 \mathrm{mM}$ spermidine, $0.15 \mathrm{mM}$ spermine, $15 \mathrm{mM} \beta$ mercaptoethanol, $0.1 \mathrm{mM}$ PMSF) and resuspended to $3 \mathrm{mg} / \mathrm{ml}$ DNA. $\mathrm{CaCl}_{2}$ was added to $1 \mathrm{mM}$ and nuclei were digested with micrococcal nuclease at $0.5 \mathrm{units} / \mathrm{ml}$ or $4.5 \mathrm{units} / \mathrm{ml}$. Digestion was carried out for 1 hour at $37^{\circ} \mathrm{C}$ after which the reaction was stopped by addition of EDTA to $5 \mathrm{mM}$ and placing the reaction mixture on ice. Nuclei were pelleted at $8000 \mathrm{~g}$ for $5 \mathrm{mins}$, then lysed by addition of $0.25 \mathrm{mM}$ EDTA pH 7.5. Typically, the volume at this stage was half that during the digest. Samples were incubated on a rocking platform for 1 hour at $4^{\circ} \mathrm{C}$. Nuclear debris and large chromatin fragments were pelleted at $8000 \mathrm{~g}$ for $20 \mathrm{mins}$, and the supernatant containing solubilized chromatin was recovered. 
The DNA concentration of the sample was determined by measuring $A_{260}$. Protein composition was analyzed by SDS-PAGE (15\% acrylamide) and chromatin fragment size was analyzed by $1 \%$ agarose gel electrophoresis. For both gel types, sample was mixed with an equal volume of 2x SDS loading buffer (100 mM Tris $\mathrm{HCl} \mathrm{pH}$ 6.8, $200 \mathrm{mM}$ DTT, $4 \%$ SDS, $0.2 \%$ bromophenol blue, $20 \%$ glycerol), and incubated for 30 mins at $37^{\circ} \mathrm{C}$ before loading. For agarose gel electrophoresis, samples were sometimes pretreated with proteinase $\mathrm{K}$. For this, samples were diluted with an equal volume of proteinase $\mathrm{K}$ buffer (10 $\mathrm{mM}$ Tris $\mathrm{HCl} \mathrm{pH}$ 7.8, $5 \mathrm{mM}$ EDTA, 0.5\% SDS), and proteinase $\mathrm{K}$ added from a $20 \mathrm{mg} / \mathrm{ml}$ stock solution to a working concentration of $50 \mu \mathrm{g} / \mathrm{ml}$. Samples were incubated for 1 hour at $45^{\circ} \mathrm{C}$, and were then prepared for electrophoresis as described above.

To remove linker histones from a chromatin preparation, the sample was first diluted to $\mathrm{A}_{260}=50(2.5 \mathrm{mg} \mathrm{DNA} / \mathrm{ml})$ with $0.25 \mathrm{mM}$ EDTA pH 7.5. To this, 0.01 volumes of $1 \mathrm{M}$ Tris $\mathrm{pH} 8$ was added, then $\mathrm{NaCl}$ was added to a final concentration of $350 \mathrm{mM}$. The sample was then incubated with $30 \mathrm{mg} / \mathrm{ml}$ carboxymethyl-Sephadex C-25 (Amersham Biosciences) for 3 hours at room temperature (?). Resin was removed by centrifugation at $8000 \mathrm{~g}$ for $25 \mathrm{mins}$, and the chromatin in the supernatant was recovered and analyzed by SDS-PAGE.

\section{CHO cell culture and chromatin preparation.}

Chinese hamster ovary cells (cell line AA8) were grown in $\alpha$-MEM (Gibco) with streptomycin and penicillin G. Cells were grown to confluence in T150 flasks, typically 4-8 flasks provided sufficient material for AFM work. When required, medium was supplemented with $5 \mathrm{mM}$ sodium butyrate from a sterile $250 \mathrm{mM}$ stock solution. For growth curves, photographs of the cells under 200x magnification were taken, and cells within a given area were counted. Nuclei from $\mathrm{CHO}$ cells were obtained using the Nuclei EZ Prep Kit (Sigma). Chromatin was extracted from CHO nuclei using essentially the same method as for CE nuclei. Four $150 \mathrm{~cm}^{2}$ flasks of confluent $\mathrm{CHO}$ cells were used for each preparation (cells grown with sodium butyrate did not achieve confluence, and were 
generally grown for 48 hours then harvested for chromatin extraction). For preparation of chromatin from cells grown with sodium butyrate, $5 \mathrm{mM}$ sodium butyrate was included in all buffers. For the nuclease digest of $\mathrm{CHO}$ nuclei, 4.5 units/ml were typically used for a 15 minute incubation.

\section{Histone purification and chromatin reconstitution.}

Histones for reconstitution experiments were purified from CE chromatin according to a published method (von Holt et al., 1989). Chromatin was dialyzed against extraction buffer (10 mM Tris $\mathrm{HCl} \mathrm{pH}$ 7.4, $0.25 \mathrm{mM}$ EDTA, $0.2 \mathrm{mM}$ PMSF). Typically, $100 \mathrm{mg}$ DNA in $20 \mathrm{~mL}$ extraction buffer was loaded onto a hydroxyapatite column in equilibration buffer (10 $\mathrm{mM}$ sodium phosphate $\mathrm{pH} 7.4,0.1 \mathrm{mM}$ PMSF). Unbound material was eluted with equilibration buffer and histones were eluted with equilibration buffer $+3 \mathrm{M} \mathrm{NaCl}$. Reconstitution of nucleosomes on a DNA template was carried out according to a published procedure (Carruthers et al., 1999).

\section{AFM imaging}

For AFM imaging, chromatin samples were extensively dialyzed against 5 mM TEA pH 7, with or without $0.1 \mathrm{mM}$ EDTA (Bustamante et al., 1997). To fix samples prior to imaging, chromatin was diluted to $0.1 \mathrm{mg} / \mathrm{ml}$ DNA and incubated overnight at $4^{\circ} \mathrm{C}$ with $0.1 \%$ glutaraldehyde. The sample was then dialyzed against $5 \mathrm{mM}$ TEA pH 7 (with or without EDTA). Freshly cleaved mica was used as a substrate for all imaging. For surface treatments, the mica was incubated for 3 mins with $3 \mu 10.001 \%$ poly-L-lysine (PLL). The mica was then washed with ultrapure water and dried under nitrogen gas. Typically, 1-2 $\mu \mathrm{l}$ of sample at $0.1 \mathrm{mg} / \mathrm{ml}$ DNA was dropped onto the center of the mica disc, and incubated for up to 3 mins. The sample was then dried with nitrogen gas, washed with ultrapure water, and dried again. Imaging was carried out with a Digital Instruments Multimode AFM or an Asylum AFM. A variety of tips were used, usually Force Modulation Silicon probes (Nanoworld) with a resonance frequency of around $75 \mathrm{kHz}$, or Pointprobe (Nanoworld) non-contact mode tips with a resonance frequency of $320 \mathrm{kHz}$. 


\section{Image analysis}

Image analysis was carried out using UTHSCSA Image tool (University of Texas Health Science Center) and Origin v7.5 (OriginLab Corporation). 


\section{Results}

\section{Samples}

The usual yield of chromatin from a 0.5 units Mnase $/ \mathrm{ml}$ digest of nuclei was $20 \%$, e.g. a prep from $7.5 \mathrm{mg}$ DNA in nuclei gave $1.5 \mathrm{mg}$ DNA in extracted chromatin. With nuclease at 4.5 units/ml the yields were somewhat higher. Either digest condition provided ample chromatin for many AFM experiments. $\mathrm{CHO}$ chromatin was produced at lower overall yield, additionally the amount of starting material was always considerably lower than that of purchased chicken blood. Four $150 \mathrm{~cm}^{2}$ flasks typically yielded $2-4 \mathrm{mg}$ DNA in nuclei, less if butyrate was included in the growth medium. Chromatin yield from nuclei was usually $10-20 \%$ for untreated cells or $5-10 \%$ for butyrate treated cells.

Figure 2 shows an agarose gel of CE chromatin fragments. The center lane of this gel shows the characteristic laddering of DNA fragments, each rung corresponding to a DNA length for an integer number of nucleosomes which was protected from digestion by the nuclease. Clearly visible in this lane is a blank zone from approximately $1600 \mathrm{bp}$ up to $3000 \mathrm{bp}$. When the sample was treated with proteinase $\mathrm{K}$ to digest away most of the histone proteins and the resulting sample was run on an agarose gel, this blank zone disappeared (Figure 2, right hand lane), showing that chromatin fragments in the size range 1600-3000 bp are indeed present in the sample, but that they migrate anomalously unless proteins are stripped from them first. The same effect of proteinase $\mathrm{K}$ was seen with $\mathrm{CHO}$ chromatin (data not shown).

Figure 3 shows agarose gels of $\mathrm{CE}$ and $\mathrm{CHO}$ chromatin fragments produced by different micrococcal nuclease digest times. As expected, longer digests result in smaller chromatin fragments: after 2 hours, most chromatin fragments are smaller than 8 nucleosomes long. Digestion time trials such as these were used with every new chromatin preparation and with every new nuclease stock to ensure that the samples isolated were of suitable size distributions. The preferred size distribution is represented by the 20 minute time point in the $\mathrm{CE}$ gel: most of the chromatin fragments are long, but 
there are shorter fragments present which aid in visualization of chromatin and ensuring that the AFM is working at good resolution. The agarose gel for $\mathrm{CHO}$ chromatin in Figure 3 shows an unusual feature not observed in the CE samples. Beginning at the $t=0$ time point and persisting, albeit less strongly, at later time points, are two nucleic acid fragments of sizes (just under $1 \mathrm{~kb}$ ) and (just over $1.5 \mathrm{~kb}$ ) bp. These fragments was never unequivocally identified (see Discussion).

SDS-PAGE analysis of CE chromatin, both native and linker histone-stripped, shows the samples to be highly pure (Figure 4). The native chromatin sample shows only the core and linker histone proteins: any additional non-histone proteins must be present at extremely low levels. The four core histones are identified in Figure 4, along with the three forms of linker histone known to be present in chicken erythrocytes. The linker histone stripping process has no effect on the levels of core histones present in the sample, as judged by the intensities of the core histone bands on SDS-PAGE gels such as this.

Figure 5 compares the protein composition of $\mathrm{CHO}$ and $\mathrm{CE}$ chromatin. $\mathrm{CHO}$ chromatin from cells grown with and without sodium butyrate are also compared. The core histones are basically identical between all three samples, but there are major differences in the linker histones and in the non-histone proteins present. CHO cells grown without butyrate in the medium show one major linker histone band (left hand lane). Those grown with butyrate show two linker histones at similar levels. Both $\mathrm{CHO}$ chromatin samples contain a large number of non-histone proteins, some at reasonably high concentrations relative to the histones. $\mathrm{CHO}$ cells growing in the presence of $5 \mathrm{mM}$ butyrate were observed to grow very slowly. This was quantified through cell counting using digital photographs of representative fields of view through a microscope. The results are shown in Figure 6. Cultures grown with sodium butyrate would generally undergo a single division and then stop. Such cultures were maintained for the time it took for untreated cells to achieve confluence in four $150 \mathrm{~cm}^{2}$ flasks. This ensured that the treated cells had sufficient time to adjust their protein expression pattern in response to the butyrate. 
An interesting effect of digest time on the protein content of $\mathrm{CHO}$ chromatin was observed and is depicted in Figure 7. CHO chromatin isolated using different nuclease digest times varies subtly in its protein content. This is particularly apparent in the linker histones and non-histone proteins, but a variant core histone was also observed to appear in moderate digest time preparations (5 and 10 mins in Figure 6). This is in marked contrast to $\mathrm{CE}$ chromatin, where the protein composition was found to be invariant, regardless of the nuclease digestion time (data not shown).

Histones were purified for nucleosome reconstitution onto lambda DNA templates. Figure 8 shows a histone elution profile from a hydroxyapatite column, along with SDSPAGE slices representing the starting material and the protein recovered from the two major peaks. Core histones were separated very efficiently from linker histones using this technique. The linker histone sample loaded onto the SDS-PAGE gel was highly concentrated, and shows up a number of non-histone proteins as well as small amounts of core histones. Consequently, although this method is suitable for isolation of core histones, isolation of pure linker histones would require further fractionation. In order to judge the efficiency of reconstitution, agarose gel electrophoresis of the samples and AFM imaging were carried out. Figure 9 shows the results of these analyses. In Figure 9a it can be seen that there is some laddering of the DNA, suggesting that nucleosomes have formed. The spacing of the ladder is not the same as that for chromatin purified from chicken erythrocytes (Figure 2), but this is to be expected since there are no linker histones present in the reconstitution, and these provide additional protection against digestion. The agarose gel cannot give an indication of the efficiency of reconstitution, it can only show that some has occurred. AFM imaging (Figure 9b) makes it clear that any reconstitution was minimal: there is a great deal of naked DNA in the image, and very few nucleosomes. What nucleosomes are visible are not as clearly defined as those from isolated chromatin (see later, Figure 10), although this may have something to do with the high levels of interfering vibrations which gave the rippled effect in the background of this image. 


\section{AFM imaging}

Figure 10 shows a typical AFM image of highly fragmented CE chromatin on PLL treated mica. This chromatin was prepared using a high concentration of micrococcal nuclease: 4.5 units $/ \mathrm{ml}$ for 1 hour. This digests the chromatin into short fragments, many of them only a few nucleosomes long. The mottled background on the mica surface is due to the presence of PLL. Many mononucleosomes are visible in this image, and the bending of the DNA as it wraps around the histones is apparent. A trinucleosome is highlighted, this fragment clearly shows the segments of linker DNA which run between adjacent nucleosomes. Measurement of the DNA shows it to have an apparent width of about $5 \mathrm{~nm}$, which is larger than the actual value of $2 \mathrm{~nm}$ (Alberts et al., 2002). This is due to the relatively much larger size of the AFM tip, which results in a broadening of features in the image. Measurements of the nucleosomes can likewise be made, they are highly uniform with a diameter of approximately $14 \mathrm{~nm}$ and a height of 3-5 nm, which agree well with data from the published crystal structure of a mononucleosome (Luger et al., 1997) and from published AFM images (Leuba et al., 1994). Different nuclease digestion times produce chromatin fragments of different sizes (see Figure 3), and this is also revealed by AFM. Figure 11 shows an AFM image of CE chromatin on PLL treated mica, but in contrast to Figure 10, this chromatin was produced by a much milder digestion protocol: 0.5 units $/ \mathrm{ml}$ for 1 hour. Most chromatin fibers visible in Figure 11 are long, very few mono- di- or tri-nucleosomes are present in this preparation. The density of nucleosomes along the DNA is not high in this image, this is probably due to the presence of PLL on the mica surface (see Discussion).

Figure 12 shows an AFM image of linker histone-stripped CE chromatin. The DNA is mostly naked, with just a few nucleosomes remaining. Most of these nucleosomes are positioned at kinks in the DNA strands. This sample was produced by mild digest of nuclei ( 0.5 units nuclease/ $\mathrm{ml}$ for 1 hour) producing very long fibers. The low density of nucleosomes along the DNA in this image is surprising given that SDS-PAGE analysis of the sample showed that the linker histone stripping process had no effect on the amount of core histones present in the sample (Figure 4). This again suggests that the presence of 
PLL on the mica surface is interfering with the chromatin fiber structure. To investigate this, it was decided to try imaging chromatin on a bare mica surface.

The efficiency of chromatin binding to plain mica is greatly reduced compared to PLL treated mica, but enough chromatin will adhere to obtain good images. Figure 13 shows such an image of CE chromatin. Some kind of higher order structure to the nucleosomes is apparent, particularly in the fiber in the upper left hand corner. Again, many stretches of naked DNA are observed, suggesting that histone proteins are easily displaced from the DNA under these conditions, most likely during the wash step of the sample preparation. (This wash step cannot be omitted, since even when depositing chromatin samples from $0.25 \mathrm{mM}$ EDTA buffer, debris/crystals were seen. We did not try deposition of chromatin from pure water, but it is doubtful that this would be any good). It proved very difficult to find an ideal concentration of chromatin sample to incubate onto bare mica. To collect the image shown in Figure 13, chromatin at $0.1 \mathrm{mg} / \mathrm{ml}$ was deposited. A very slight increase in concentration of sample to $0.5 \mathrm{mg} / \mathrm{ml}$ produced the very crowded image of Figure 14. Some fibers are well defined in this image, but for the most part it is impossible to tell where one fiber ends and another begins. The factors governing the efficiency of chromatin binding to bare mica could not be determined. Sample concentration, buffer conditions, ionic strength were all varied but no consistent pattern emerged.

The natural progression from this point is to compare the unfixed, native chromatin samples which have been described so far with those of fixed chromatin. Figure 15 shows glutaraldehyde fixed CE chromatin deposited on bare mica. The structure of the fibers is retained in these samples compared to unfixed ones (compare with Figure 13). The basic nature of the chromatin is unchanged: nucleosome diameter and height, and DNA width appear very similar in fixed and unfixed samples, suggesting that the fixation process has not unduly altered the natural structure. A selection of fixed CE chromatin fibers are shown in Figure 16. The scale bar in all images is $50 \mathrm{~nm}$, and it can be seen that there are chromatin fibers of several thicknesses. 
Linker histone-stripped CE chromatin also gives better images better in the AFM if it is fixed first: Figure 17 shows several images of linker histone-stripped CE chromatin on bare mica. Comparison of this image with Figure 12 shows that the fix step results in more nucleosomes being retained on the DNA strand, while the actual appearance of the nucleosomes and the DNA is unchanged.

CHO chromatin was imaged on plain mica (Figure 18). These fibers were glutaraldehyde fixed and imaged as for CE chromatin. In general, much smaller fibers were seen for $\mathrm{CHO}$ chromatin (compare Figure 18 with Figure 16). Imaging of CHO chromatin on PLL treated mica was not carried out, due to its denaturing effect on CE chromatin (Figures 10 and 11), and in any case, $\mathrm{CHO}$ chromatin was observed to stick to plain mica reasonably well, although less efficiently than CE chromatin. Occasionally, very large aggregates of fixed CHO chromatin would be observed (Figure 19). This was never seen for CE chromatin, even though the fixation procedure was identical for both samples. It is highly unlikely that the aggregate in Figure 19 represents just one or a few chromatin fibers, based upon the DNA fragment sizes seen in agarose gels for this sample (Figure 3). Many short ( $<5$ nucleosomes) chromatin fibers are visible in Figure 19, but it appears that any longer fibers present in the sample must be bound up in the aggregate at the bottom of the image.

Images of $\mathrm{CHO}$ and $\mathrm{CE}$ chromatin were analyzed, with nucleosome diameters and center-center distances being measured. The results of this analysis are presented in Table 1; histograms of the results are presented in Figure 20. Measured nucleosome diameters were found to fit well to a Gaussian curve (solid lines Figure 20), means and standard errors shown in Table 1 are from this fit. Center-center distances were not well modeled in this way. 


\begin{tabular}{|c|c|c|}
\hline Sample & Nucleosome diameter & Center-Center distance \\
\hline CE & $14 \pm 2$ & $19 \pm 4$ \\
\hline CE (linker histone-stripped) & $14 \pm 2$ & $37 \pm 11$ \\
\hline CHO & $14 \pm 2$ & $20 \pm 6$ \\
\hline
\end{tabular}

Table 1. Nucleosome diameters and center-center distances measured from AFM images. Values of the mean and standard error are given in $\mathrm{nm}$. 


\section{Discussion}

\section{Samples}

The yields of chromatin obtained from the two cell types were low but were perfectly sufficient for use in AFM, which requires only very small amounts of sample. Nevertheless, improvement in the yield of chromatin from $\mathrm{CHO}$ cells would be advantageous, particularly in the case of sodium butyrate treated cells, which would often barely grow at butyrate concentrations of $5 \mathrm{mM}$ (Figure 6). This concentration was chosen based on published work on the effects of butyrate on CHO cells (D'Anna et al., 1980). It is possible that different strains of $\mathrm{CHO}$ cell have different tolerances to butyrate, and so a more complete study of the concentration dependence of butyrate on the growth of AA8 CHO cells would be worthwhile.

In Figure 2, it can be seen that $\mathrm{CE}$ chromatin fibers of more than 8 nucleosomes in length migrate anomalously in an agarose gel leading to a gap in the DNA ladder from about 1.6 to $3 \mathrm{~kb}$. This has been reported in the literature before (Zlatanova et al., 1994), although the gap was seen in a slightly different position: starting at 6-mer nucleosome fibers rather than 8-mer fibers as in this report. Pre-treatment of the samples with proteinase $\mathrm{K}$ to digest the histones makes DNA fragments of more than $1.6 \mathrm{~kb}$ run normally in the gel (Figure 2, right hand lane). It is plausible that a fiber of more than 8 nucleosomes is able to form a structure which is resistant to denaturation under the conditions used to prepare samples for agarose gel electrophoresis $\left(37^{\circ} \mathrm{C}\right.$ for 30 mins in SDS-loading buffer). Further experiments to investigate this are possible: a very high molecular weight size exclusion protocol or ultracentrifugation to enrich a sample in chromatin fibers of around this size could be carried out, followed by AFM imaging and analysis of the most commonly seen structures in 8- to 10-mer nucleosomes. The gap in the agarose gel was not seen in linker histone-stripped samples, suggesting a need for linker histones in formation of such a resistant structure. 
Sample quality was determined to be very important in obtaining good quality images by AFM. CE chromatin had no detectable non-histone contaminants (Figure 4), and extensive dialysis to remove excess salts and other small molecules was always carried out. These two factors were the main determinants of AFM image quality. In contrast, $\mathrm{CHO}$ chromatin contained a number of non-histone proteins (Figure 5) which varied a little between different preparations. Another source of impurity in the $\mathrm{CHO}$ chromatin samples is shown in Figure 3. Two nucleic acid fragments of just under $1 \mathrm{~kb}$ and just over $1.5 \mathrm{~kb}$ were present in many, but not all, of the $\mathrm{CHO}$ chromatin samples used in this study. The possibility that RNA was copurifying with chromatin was investigated by pretreating samples with RNAse prior to agarose gel electrophoresis. Such treatment did not significantly reduce the intensity of these bands (data not shown), suggesting that RNA was not the cause; however, if the RNA had significant secondary structure, it may not have been fully digested under the conditions used. Because these nucleic acid fragments were not always present in a $\mathrm{CHO}$ chromatin preparation, and because the AFM images of $\mathrm{CHO}$ chromatin were indentical whether or not the fragments were there, further study was not undertaken.

CHO chromatin was much harder to image than CE chromatin, and the presence of nonhistone proteins is the most likely cause. These imaging difficulties were manifested as a tendency for only small fibers to adhere to the mica surface (see Figure 18), and a clumping of fibers during either the fixation process or the incubation on mica (see Figure 19). Mica is negatively charged, and chromatin itself is only weakly positively charged: the strongly positive histones being mostly neutralized by the negative charges of the DNA backbone. Consequently, the interaction between chromatin fibers and a plain mica surface is relatively weak. Drying the sample down onto the mica forces the fibers to stick, but the interaction was far too weak to allow imaging under fluid.

Why then would CE chromatin adhere more strongly to mica than $\mathrm{CHO}$ chromatin? Our hypothesis is that the additional non-histone proteins in the $\mathrm{CHO}$ fibers act to screen out the weak interaction between chromatin and mica, and that only smaller fibers which lack 
some of these additional proteins are able to adhere firmly enough to survive the washing process and be imaged.

Attempts were made to remove the non-histone proteins from $\mathrm{CHO}$ chromatin (see Figure 7). Low salt concentrations were used to try to dissociate these proteins from the chromatin fibers. Carboxymethylcellulose was included to bind any released proteins, which could then be removed by centrifugation. Unfortunately, this method removed linker histones as well: conditions could not be found under which only non-histone proteins could be released from the fibers. Other techniques to further purify $\mathrm{CHO}$ chromatin were not developed, as it was decided to work with the samples we had rather than move in the direction of even more biochemistry.

The presence of these non-histone proteins in the $\mathrm{CHO}$ chromatin samples is not surprising. $\mathrm{CHO}$ cells are actively growing: transcribing and replicating their DNA. The protein machines which carry out these processes are present at high concentrations in the nucleus, and many of them bind to DNA or chromatin vey strongly. CE chromatin on the other hand is a heavily silenced form of chromatin. Once the erythrocyte has fully differentiated, it has no further use for its chromatin, and compacts it tightly with special linker histones. This makes CE chromatin perfect as a sample for AFM, but it does not represent the chromatin of a typical cell. It is for this reason that we chose to compare the structures of $\mathrm{CE}$ chromatin with those of the transcriptionally active $\mathrm{CHO}$ cell. It was not anticipated that the presence of certain replication, transcription and remodeling proteins would so limit our ability to image $\mathrm{CHO}$ chromatin. Nevertheless, some inroads have been made, which will be discussed in the next section.

Reconstitution of chromatin fibers from purified histones and lambda phage DNA was carried out to serve as a reference structure for the $\mathrm{CE}$ and $\mathrm{CHO}$ chromatin. Unfortunately, the reconstitution occurred with poor yield (Figure 9b), and since the CE chromatin images obtained were highly reproducible, it was decided not to further pursue the reconstitution work here. 


\section{AFM Imaging}

Imaging chromatin on PLL treated mica resulted in good quality images but highly altered structures. From Figures 10 and 11, it seems likely that the DNA binds to the PLL surface, but can then no longer bind histone so efficiently. Histones are very positively charged proteins, so they are probably displaced when the DNA sticks to the PLL. Judging from the number of loops and bends visible in the naked DNA strands in Figure 11 , some of the curvature of the DNA due to wrapping of the double helix around the nucleosome is preserved, even when the histone proteins themselves are lost. Similar comparison can be made for linker histone-stripped chromatin. The areas of naked DNA visible in images of fixed linker histone-stripped chromatin (Figure 17) are much more stretched out than those of unfixed chromatin incubated on PLL treated mica (Figure 12). This suggests that in the latter case, chromatin is contacting the surface in its native conformation and that the highly positively charged PLL causes dissociation of a large fraction of the nucleosomes. The DNA which is left behind remains in a conformation reflecting its curvature while nucleosomes were still bound. Fixed chromatin on plain mica tends to lie in a highly linear fashion (Figure 17), which is likely due to the drying procedure: carefully directional drying has been shown to align DNA linearly for AFM (Li et al., 1998).

Glutaraldehyde fixation removes these artefacts, and enough chromatin adheres to plain mica that we can eliminate the PLL treatment altogether and still obtain good images. Fixation may also help to prevent artefactual structures caused by the drying down of a three-dimensional fiber onto a two-dimensional surface. The natural alignment of the disc-shaped nucleosome on mica appears to be wide face down, to minimize contact between the negative charges of the mica and the DNA backbone. In an unfixed sample, this will automatically cause torsion or unwinding of the fiber as nucleosomes twist to make the most thermodynamically favorable contact with the surface.

The images of fixed CE chromatin (Figures 15 and 16) show the $30 \mathrm{~nm}$ fibers which have previously been described as a higher order chromatin structure (Leuba et al., 1994; 
Thoma et al., 1979; Wolffe, 1998). Thicker fibers are also seen. The $30 \mathrm{~nm}$ fiber was originally named based on the recurrence of fibers of this size in electron microscopy studies. Two models have been proposed to explain the arrangement of nucleosomes within the $30 \mathrm{~nm}$ fiber: the solenoid model and the two-start helix. In the solenoid model, a linear array of nucleosomes is coiled into a helix (Finch and Klug, 1976). In the twostart helix model, nucleosomes are arranged into a zigzag ribbon which twists into a helix (Woodcock et al., 1984). Evidence is currently leaning in favor of the two-start model: recently, the X-ray structure of a reconstituted tetranucleosome was solved (Schalch et al., 2005). The structure is incompatible with the solenoid model but fits the two-start helix very well. Earlier biochemical work from the same group also supports this model (Dorigo et al., 2004). The only caveat to this work is that it was all performed on chromatin reconstituted from purified histones and a DNA strand constructed from repeating units of a sequence known to support a very stable nucleosome structure. As such, these chromatin samples do not necessarily reflect the structure of chromatin in a living, growing cell. However, it will be interesting to see if the structure of the tetranucleosome can be easily fitted into chromatin fibers seen by AFM and electron microscopy. Even in CE chromatin, which has a very homogenous structure, clear helical arrangement of nucleosomes is not seen (Figure 16). How much this is due to the heavy contraints imposed on the crystal structure and the much looser constraints on a free floating (albeit glutaraldehyde fixed) CE chromatin fiber, and how much is due to fundamental differences between the composition of the chromatin fibers under consideration, is not yet clear. A great deal of further work will no doubt be inspired by the tetranucleosome structure in an attempt to reveal its relevance to chromatin in the cell.

The images of $\mathrm{CHO}$ chromatin in Figures 18 and 19 are, to our knowledge the first obtained for chromatin from this cell type. As was alluded to in the introduction, chromatin structure can be expected to vary greatly according to cell type. Chicken erythrocytes are highly specialized, the chromatin inside them being highly compacted and silenced. The homogeneity of CE chromatin and its ease of purification made it an excellent choice for initial AFM studies (e.g. Leuba et al., 1994), but in order to 
understand the affects of chromatin structure on transcription, repair and replication, different cell types must be used. HeLa cells have very recently been used as a source of chromatin for AFM studies (Kepert et al., 2005), but otherwise, the CHO chromatin images presented in this report are among the first and the few for chromatin from transcriptionally active cells. The $\mathrm{CHO}$ cells used in this research were chosen for their ease of growth and the range of mutant lines available, which allow for more involved experiments to investigate chromatin structure in, for example, DNA repair deficient cells.

Given the differences in protein content and cellular context between the $\mathrm{CE}$ and $\mathrm{CHO}$ chromatin used in this project, it is perhaps surprising that the AFM images show very similar strucures for each. At the level of the individual nucleosome, $\mathrm{CE}$ and $\mathrm{CHO}$ chromatin are indistinguishable (Figure 20 and Table 1). In both types of chromatin, nucleosomes were $14 \mathrm{~nm}$ in diameter, which is in excellent agreement with published values from both the X-ray crystal structure (Davey et al., 2002; Luger et al., 1997) and AFM imaging (Leuba et al., 1994). Nucleosome heights ranged from 3-5 nm in all samples, again in good agreement with published data. The distribution of nucleosomes on the DNA strands was similar for both chromatin types, the center-center distance ranging from $19 \mathrm{~nm}$ for $\mathrm{CE}$ and $20 \mathrm{~nm}$ for $\mathrm{CHO}$. When linker histones were removed from $\mathrm{CE}$ chromatin, the individual nucleosomes remained unchanged, but it could be seen that the fiber unraveled into a 'beads on a string' morphology (Figure 17) with a concomitant increase in the average spacing of nucleosomes to $37 \mathrm{~nm}$ (Figure 20 and Table 1). The distribution of center-center distances in linker histone-stripped CE chromatin is very broad, most likely due to the fact that the stripping procedure is not $100 \%$ efficient, so some nucleosomes remain in close proximity to their nearest neighbor (this can be seen in the image in Figure 17). Additionally, if there is any loss of core histones from the DNA during the linker histone stripping or fixation procedures, then the spacing between adjacent nucleosomes will appear to double.

Major differences in structure between $\mathrm{CE}$ and $\mathrm{CHO}$ chromatin might be expected at the level of the $30 \mathrm{~nm}$ fiber, and unfortunately such fibers were not observed in $\mathrm{CHO}$ 
chromatin preparations. As described above, this may be due to the presence of nonhistone proteins in the $\mathrm{CHO}$ samples affecting the chromatin-mica interaction. Further work to improve the purity of the $\mathrm{CHO}$ chromatin preparation will be needed to determine whether there are differences in chromatin structure at the $30 \mathrm{~nm}$ fiber level.

$\mathrm{CHO}$ chromatin from cells grown in the presence of sodium butyrate was not imaged successfully, due to the poor yield of chromatin from such cells and the low efficiency of binding large $\mathrm{CHO}$ chromatin fibers to mica. The presence of alternative linker histones in butyrate treated $\mathrm{CHO}$ chromatin is interesting (Figure 5), and imaging of such samples to compare with untreated $\mathrm{CHO}$ chromatin may show modification of fiber structure. Further purification of the sample would likely be required to remove the non-histone proteins which may mask any effects of the alternative linker histones.

Originally included in this LDRD proposal was work using the AFM to manipulate individual chromatin fibers, and to use the force-measuring capability of the AFM to measure the strengths of the interactions within the chromatin. Such measurements have been carried out on other macromolecules (see Zlatanova et al., 2000 for review) but only once on chromatin (Leuba et al., 2000). Optical tweezers have been a more popular technique for probing the forces required to unravel chromatin (e.g. Bennink et al., 2001; Cui and Bustamante, 2000; Pope et al., 2002). However, optical tweezers cannot be used to manipulate short fibers. Typically, researchers have used lambda DNA reconstituted with core histones. Though extremely useful in chromatin study, these fibers are not very natural. It was our belief that the AFM could be used to manipulate shorter pieces of chromatin isolated from living cells, which would therefore have a greater physiological relevance (linker histones would be there, we could compare transcriptionally active vs. inactive, or different cell types). Unfortunately, during the course of the project, work was published which cast doubt on the efficacy of the AFM for this purpose. BrowerToland et al. published work using optical tweezers to stretch a reconstituted chromatin fiber to breaking point, and were able to measure the force required to unravel successive nucleosomes (Brower-Toland et al., 2005). The forces they measured were of the order of $10 \mathrm{pN}$ : this is approximately the lower limit of force measurement with an AFM under 
excellent conditions. Furthermore, the group were able to measure the difference in force required to unravel hypoacetylated nucleosomes compared to normal nucleosomes. The difference was 1-2 pN, far below what the AFM would be able to detect. In light of this research, it seemed unlikely to us that this part of the original proposal was worth pursuing. Changes in the proposal plan were made, and two of the main strategies are outlined below for the benefit of future researchers who may find an interest in this field.

Firstly, it is proposed that purification of different $\mathrm{CHO}$ chromatin fractions based on variable nuclease digest time (see Figure 7) could be achieved. If the chromatin fractions released by short digest times are substantially different to those at later digest times, this may be reflected in changes in the fiber structure which could be detected by AFM. Analysis of the protein content of these samples would be needed to correlate any structural changes seen to the kind of chromatin being imaged: e.g centromeric or telomeric chromatin, chromatin with regions of DNA damage, or chromatin undergoing DNA replication.

Secondly, to more accurately purify select regions of $\mathrm{CHO}$ chromatin, immunopurification may be used. A wide range of antibodies to chromatin proteins are available (e.g. from Upstate), for example to the alternative core histone H2AX, known to accumulate in chromatin with DNA damage. Such antibodies can be immobilized on a Sepharose column, and the chromatin containing the protein of interest run through. Bound chromatin fibers may be eluted by addition of excess peptide epitope. Mild or incomplete glutaraldehyde fixation of the sample prior to chromatography may be recommended to prevent nucleosome loss during preparation. In this way, chromatin enriched in certain proteins may be compared to bulk cellular chromatin. 


\section{Conclusion}

Chromatin fibers were isolated from chicken erythrocytes and CHO cells. AFM imaging of these samples showed no significant differences at the level of individual nucleosomes. Unfortunately, large fibers of $\mathrm{CHO}$ chromatin were not observed by AFM, so comparison of higher level packing of nucleosomes in the two cell types could not be made. Improvements in the purity of the $\mathrm{CHO}$ chromatin samples is likely needed to obtain suitable images for such work. Nevertheless, AFM images of CHO chromatin were obtained, these are the first such images of chromatin from this cell type. It was also found that $\mathrm{CHO}$ chromatin could be extracted with varying protein composition, possibly reflecting different states of the chromatin fiber. Imaging these samples may provide interesting insight into the different structures that chromatin can take in a transcriptionally active cell. 
a.

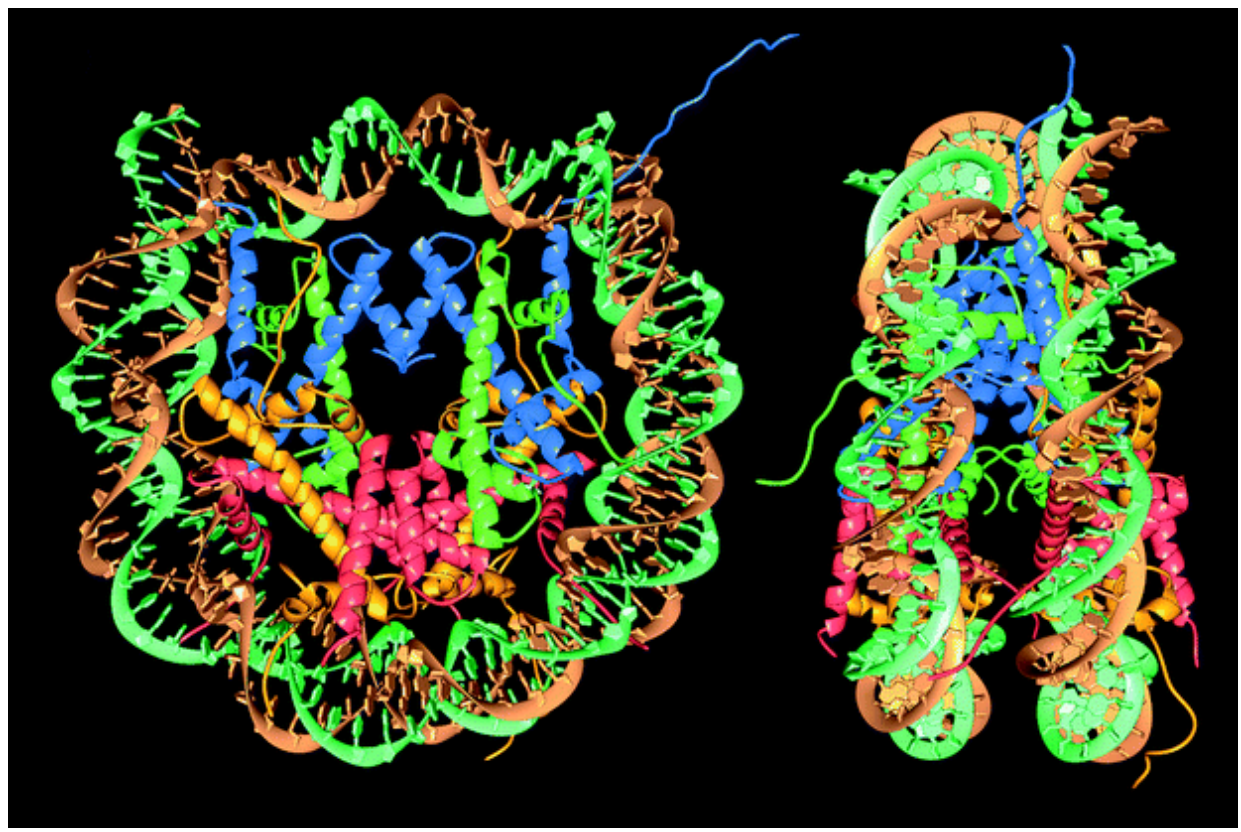

b.

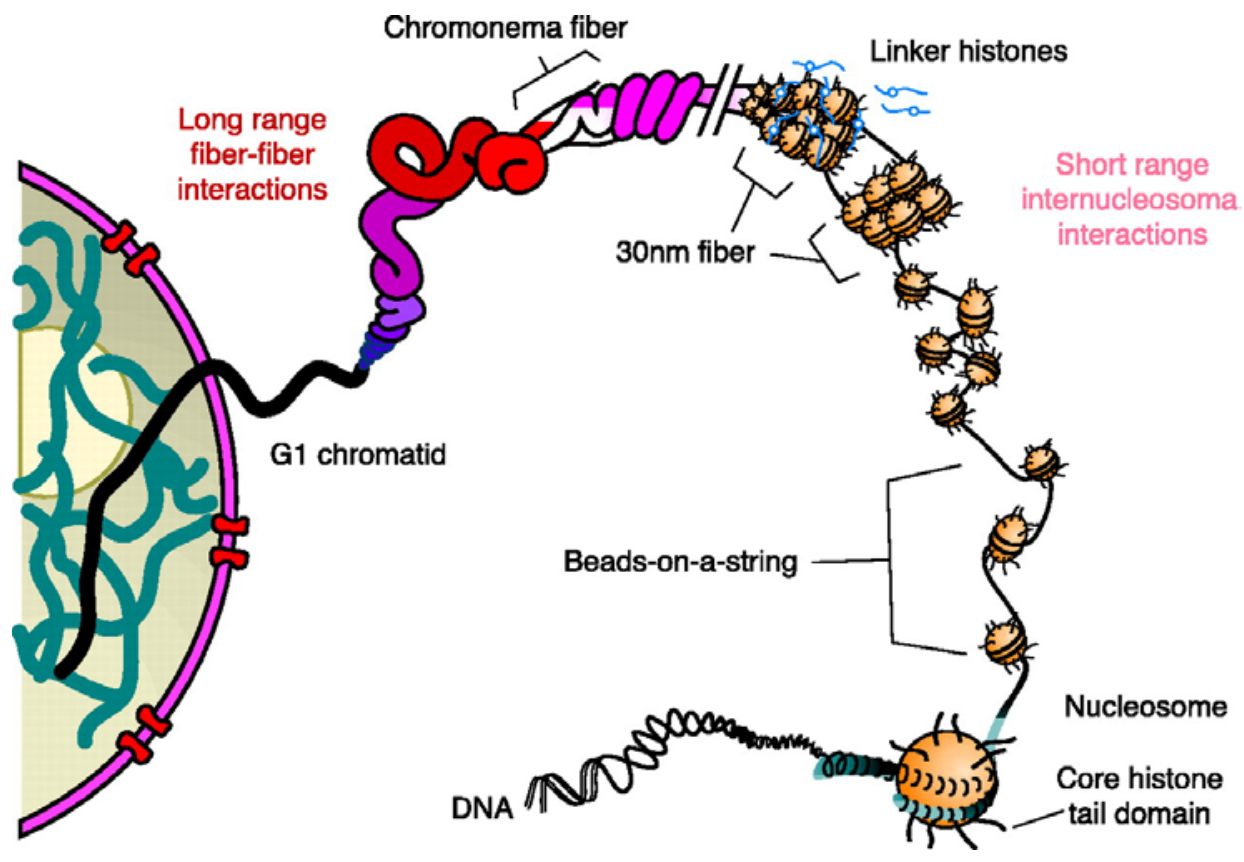

Figure 1. a) X-ray crystal structure of mononucleosome. Taken from Luger et al., 1997.

b) Schematic diagram of chromatin structure. Taken from Horn and Peterson, 2002. 


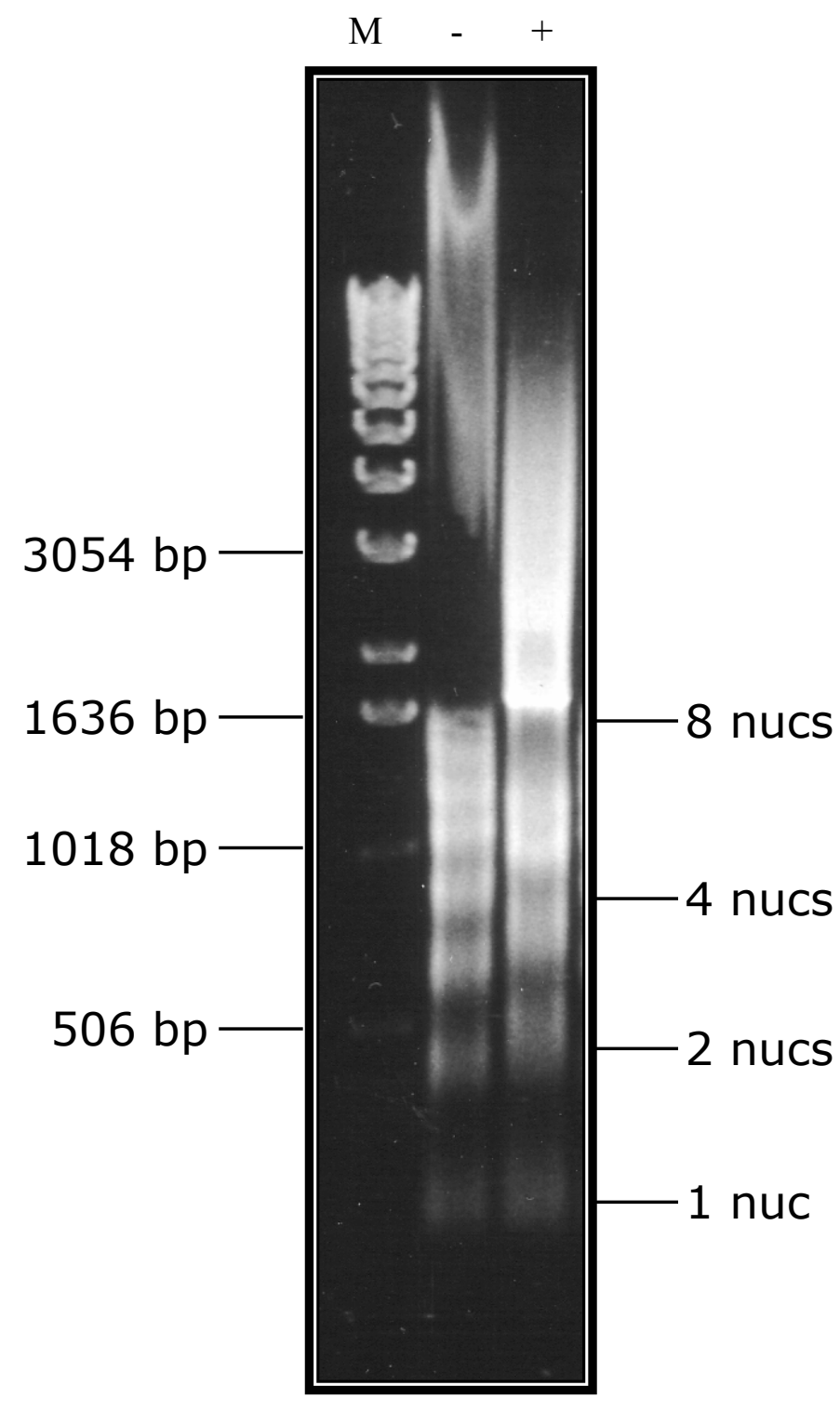

Figure 2. Agarose gel showing effect of proteinase K treatment on CE chromatin. Left lane (M) shows DNA standards; center lane (-) shows CE sample. The sample in the right hand lane $(+)$ was treated with proteinase K prior to running on the gel. For both samples, $2 \mu \mathrm{g}$ DNA were loaded per lane on a 1\% agarose gel. 

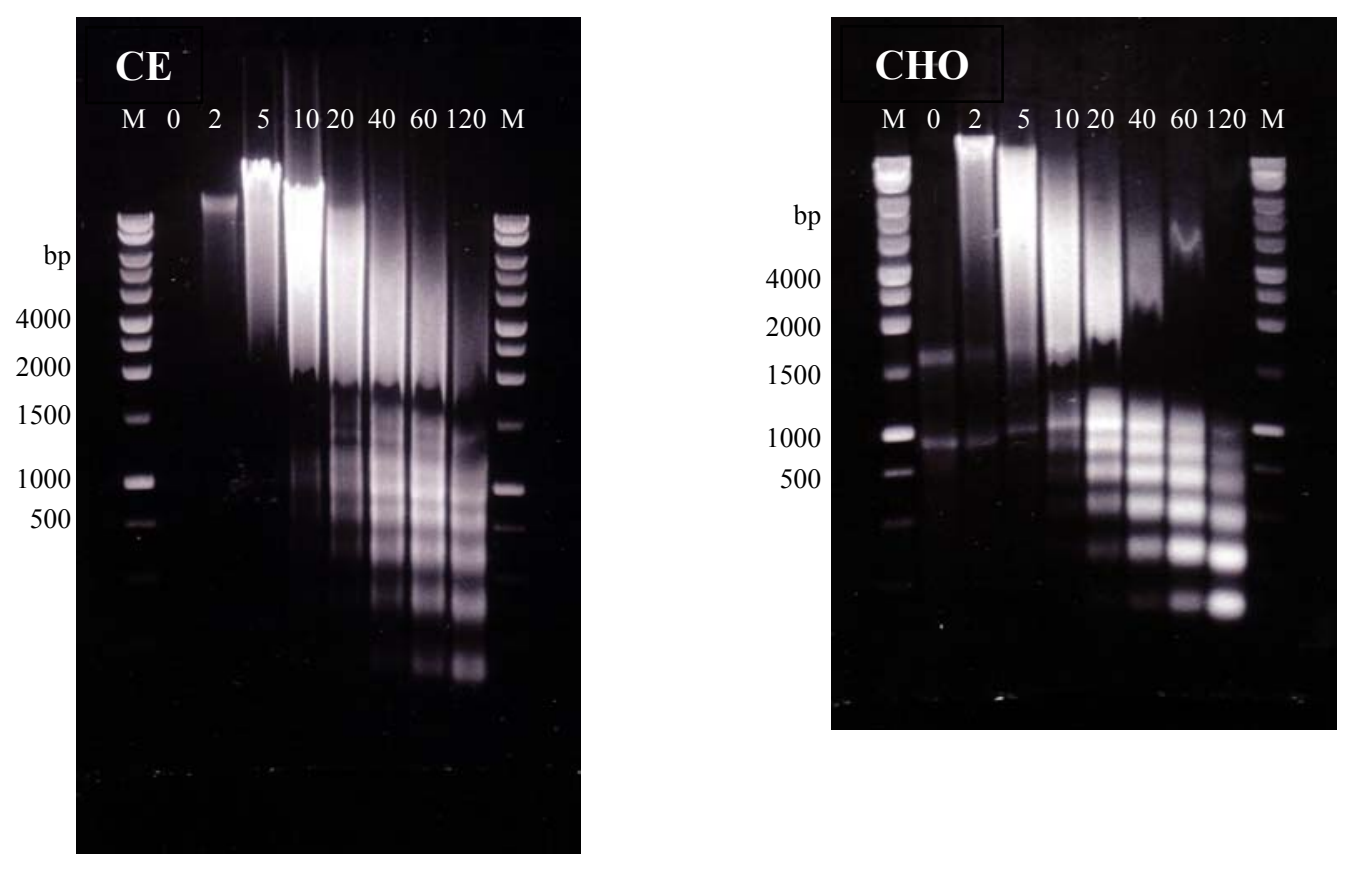

Figure 3. Effect of increasing micrococcal nuclease treatment of nuclei on chromatin fragment sizes released. Outer lanes show DNA standards, the sizes (in base pairs) of several of these bands are shown on the left. Digests were stopped at 0, 2, 5, 10, 20, 40, 60 and 120 mins, and $1 \mu \mathrm{g}$ DNA was loaded per lane. 


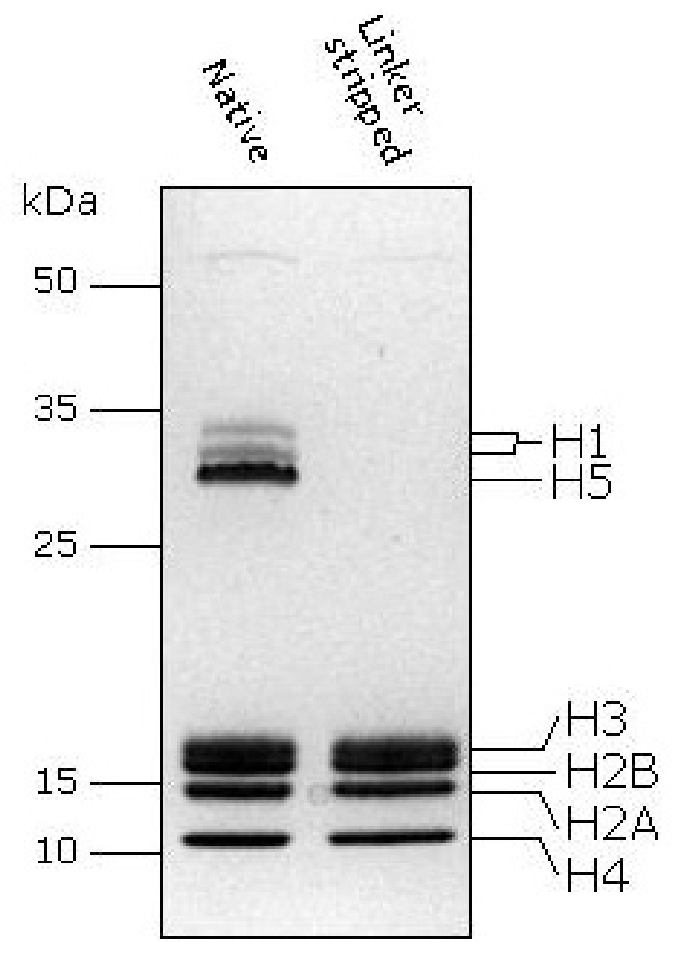

Figure 4. SDS-PAGE gel of native and linker histone-stripped CE chromatin: Chromatin containing $2 \mu \mathrm{g}$ DNA was loaded per lane. Positions of molecular weight markers are shown on the left, identification of major protein bands is shown on the right. 


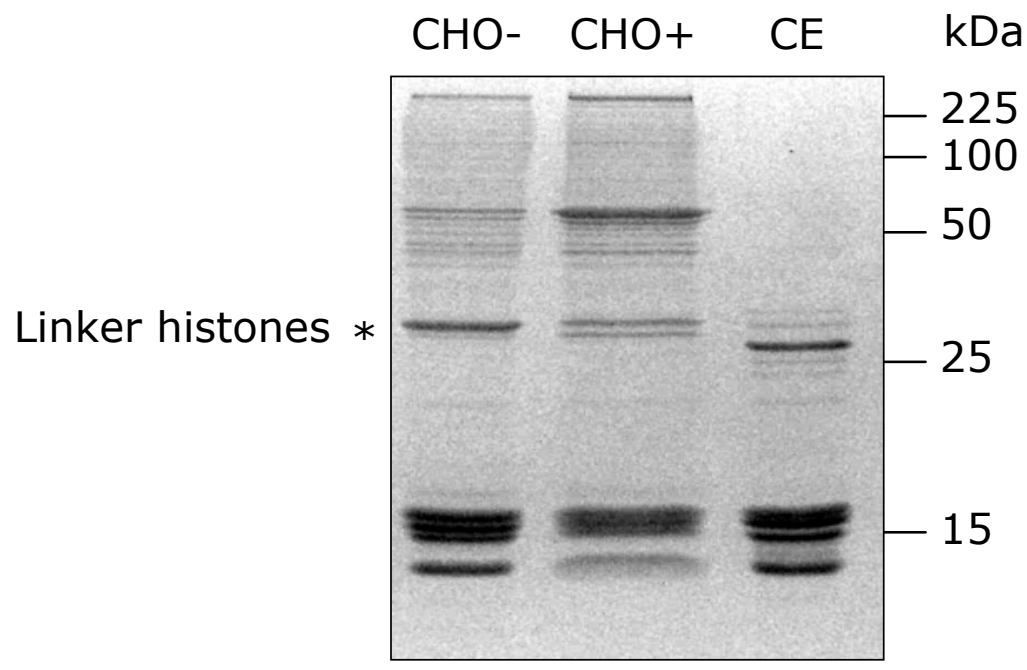

Figure 5. SDS-PAGE gel of CE and CHO chromatin samples: $2 \mu \mathrm{g}$ DNA were loaded per lane. $\mathrm{CHO}$ chromatin was prepared from cells grown in the presence $(\mathrm{CHO}+)$ and absence (CHO-) of sodium butyrate. Positions of molecular weight markers are shown on the right, position of linker histone bands is indicated on the left. 

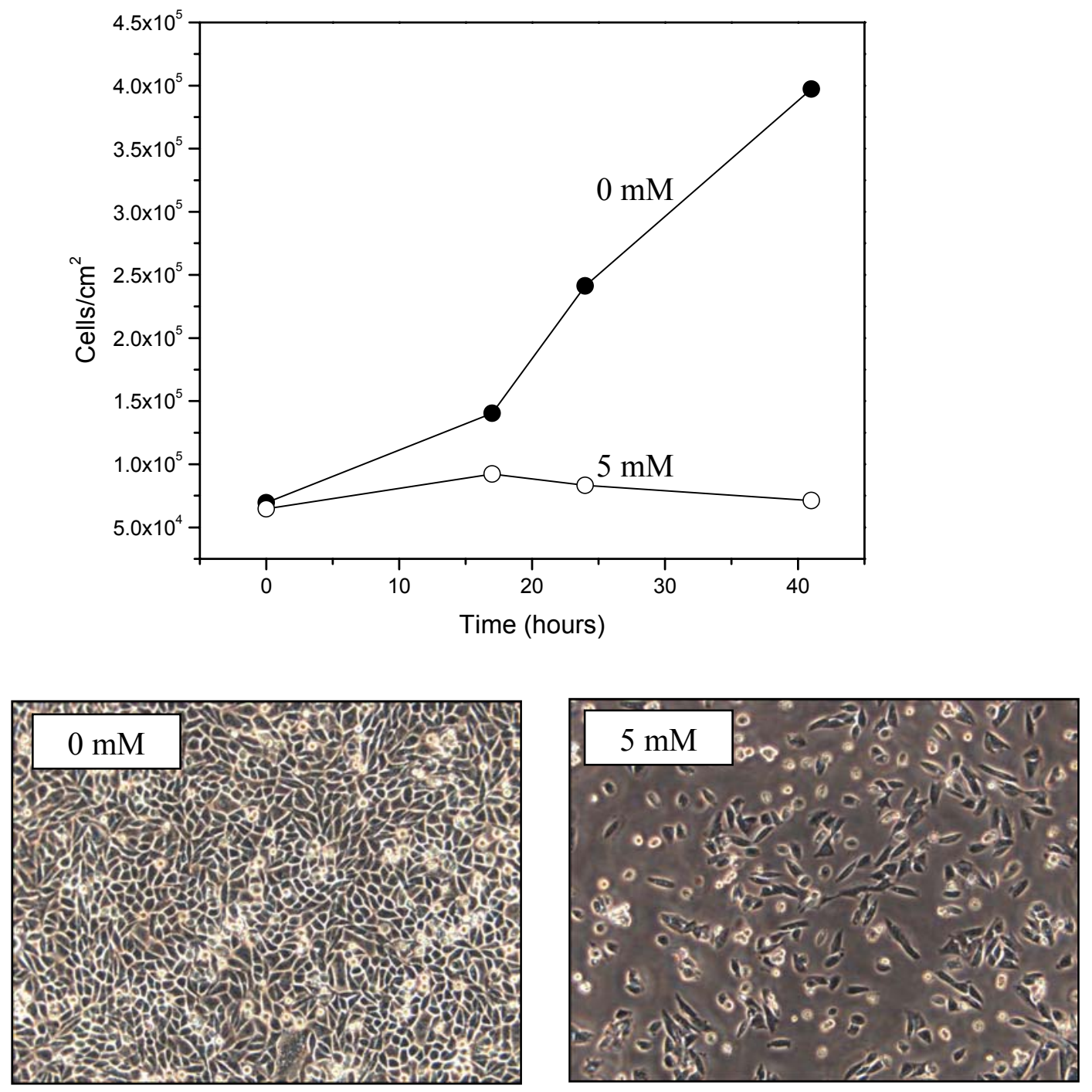

Figure 6. Effect of sodium butyrate on $\mathrm{CHO}$ cell growth. Growth curves are for $\mathrm{CHO}$ cells in $\alpha$-MEM at $0 \mathrm{mM}$ sodium butyrate (closed symbols) and $5 \mathrm{mM}$ sodium butyrate (open symbols). Photos show typical cell densities at 40 hours. 


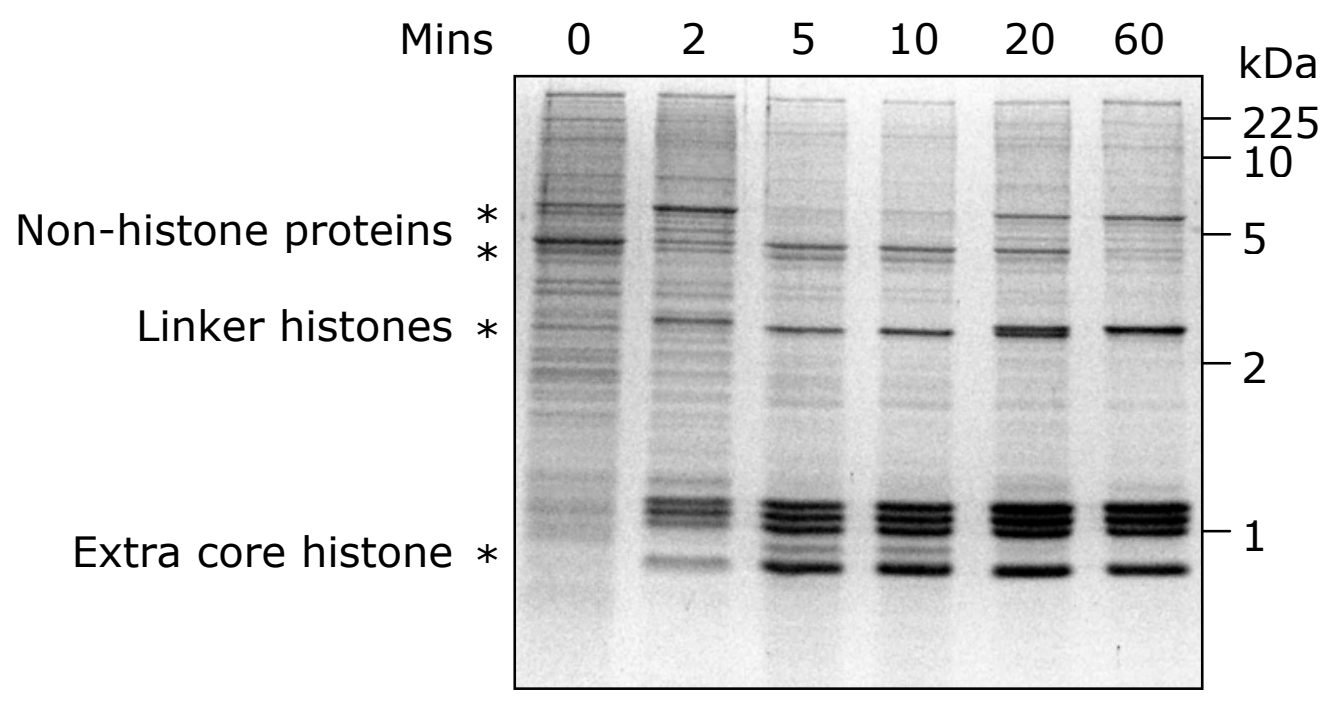

Figure 7. SDS-PAGE gel of CHO chromatin samples digested with micrococcal nuclease for varying amounts of time. Positions of molecular weight markers are shown on the right, identity of protein bands is indicated on the left. 

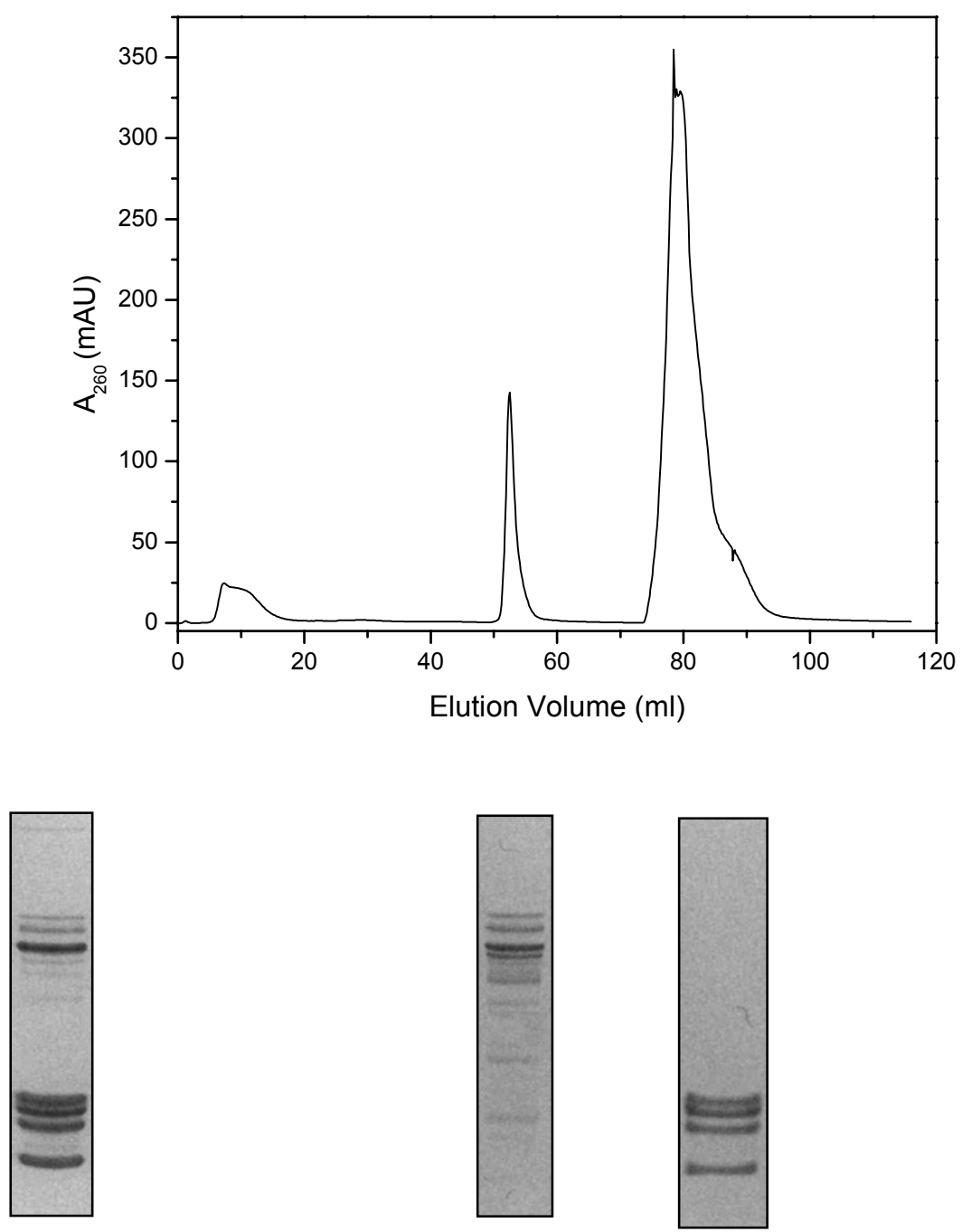

Start

Linker Core

Figure 8. Elution profile of CE histones from a hydroxyapatite column. SDS-PAGE gel slices show the protein composition of the starting material, the first peak eluted (linker histones) and the main peak (core histones). 
a)

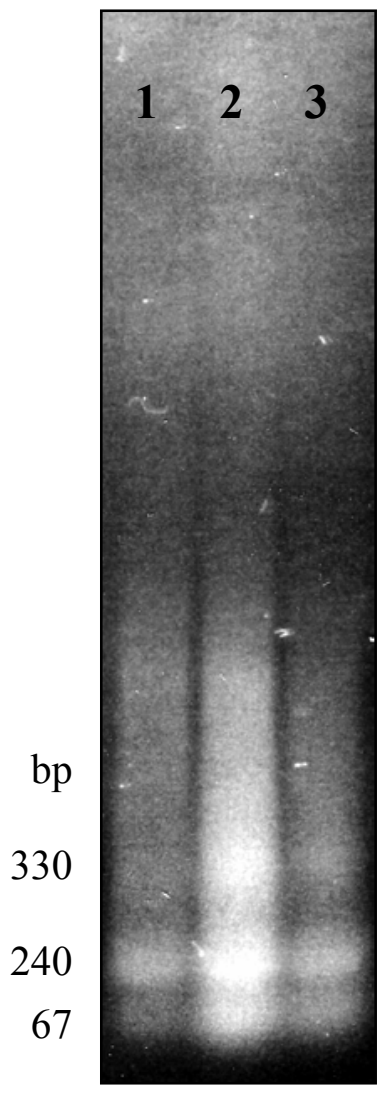

b)

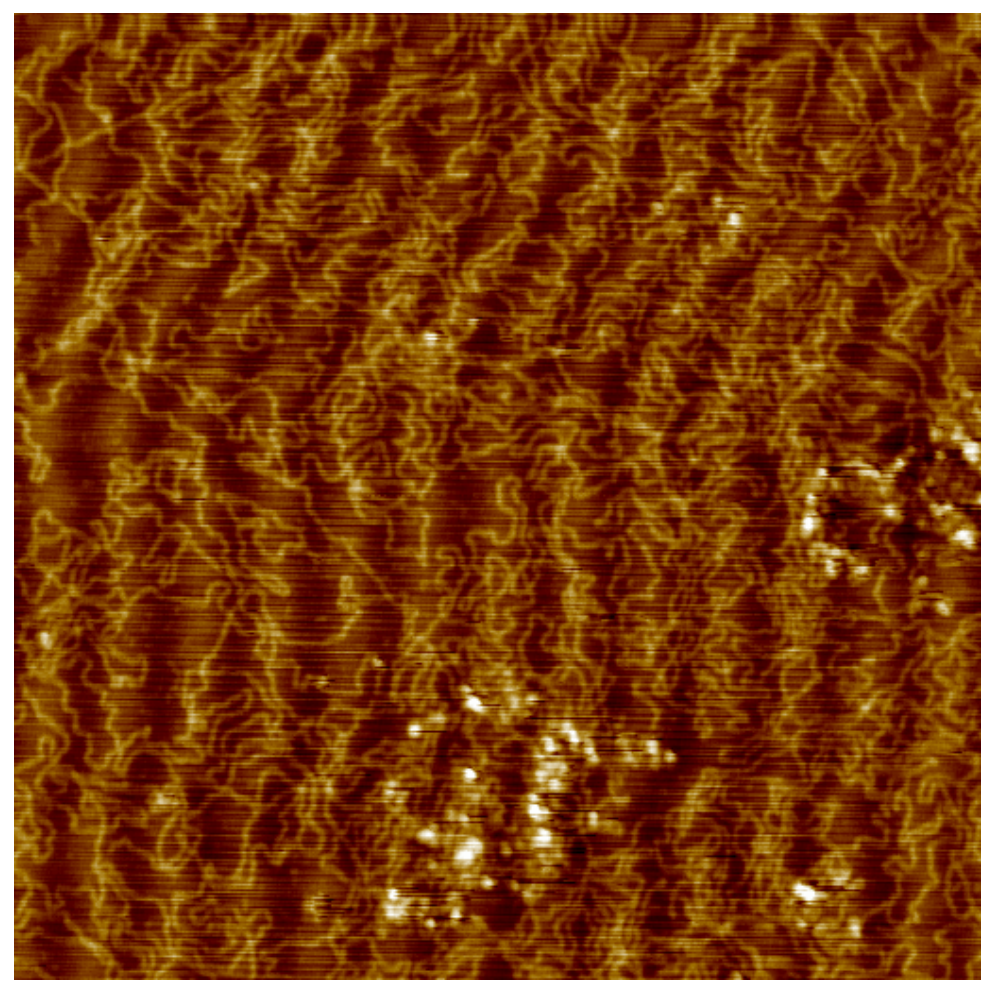

Figure 9. Reconstitution of CE histones onto $\lambda$ DNA. b) Agarose gel electrophoresis of chromatin formed through reconstitution of CE histones onto $\lambda$ DNA at a DNA:protein ratio of 1:1 (lane 1), 1:1.15 (lane 2), 1:2 (lane 3). Approximate sizes of major bands observed is indicated on the left. b) AFM image of reconstituted chromatin (1:1.15 ratio of DNA to protein) on mica. Image is $1.1 \mu \mathrm{m}$ square, height scale is $0-5 \mathrm{~nm}$ (black to white). 


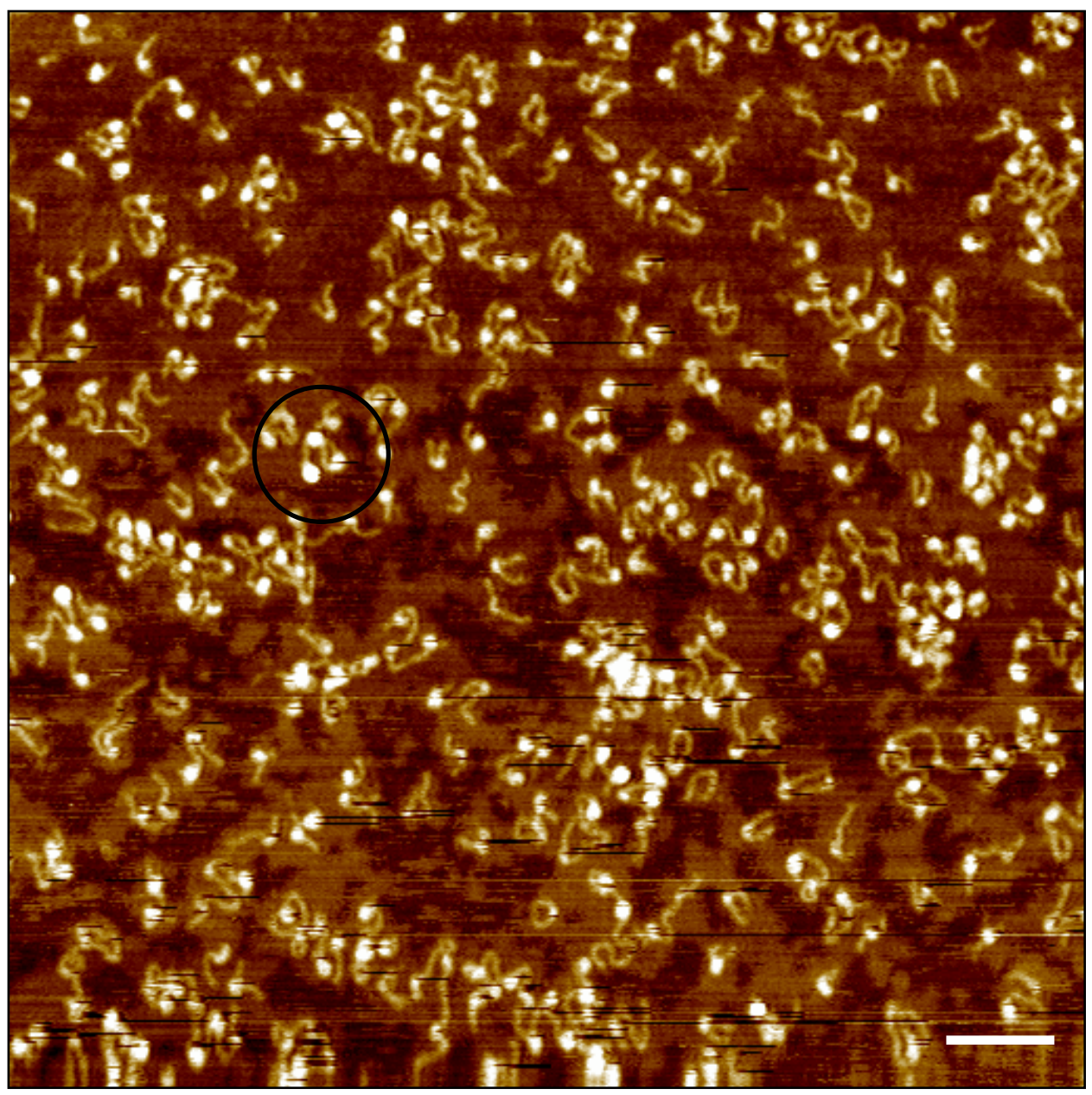

Figure 10. AFM image of CE chromatin on poly-L-lysine treated mica. Sample was an over-digested prep, hence fibers are short. Scale bar $100 \mathrm{~nm}$, height scale $0-5 \mathrm{~nm}$. The circled tri-nucleosome shows clear DNA linker segments running between successive nucleosomes. 


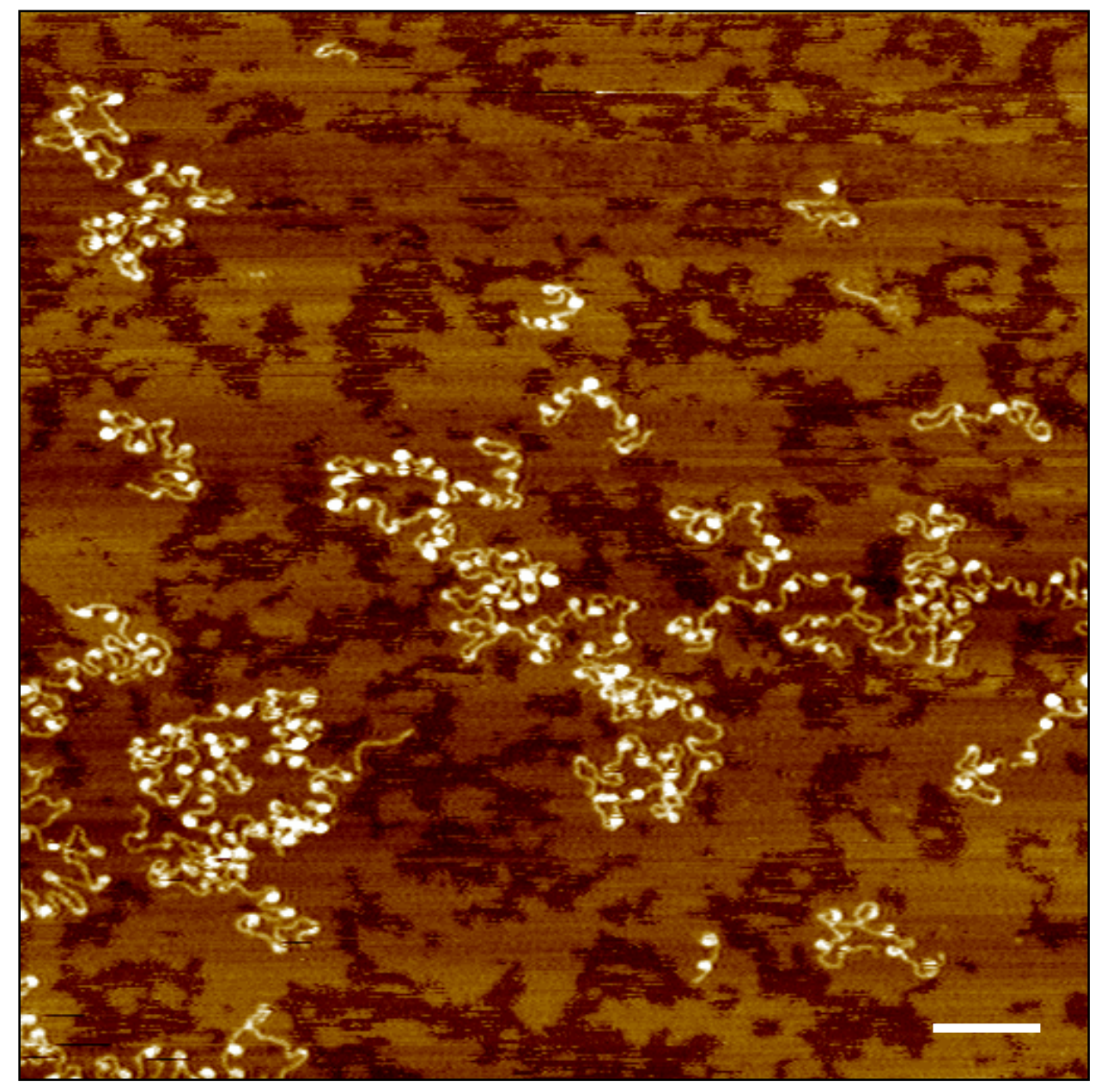

Figure 11. AFM image of CE chromatin on poly-L-lysine treated mica. Sample was digested with nuclease for a shorter time than that shown in previous figure, hence the fibers are longer. Scale bar is $100 \mathrm{~nm}$, height scale 0-5 nm. 


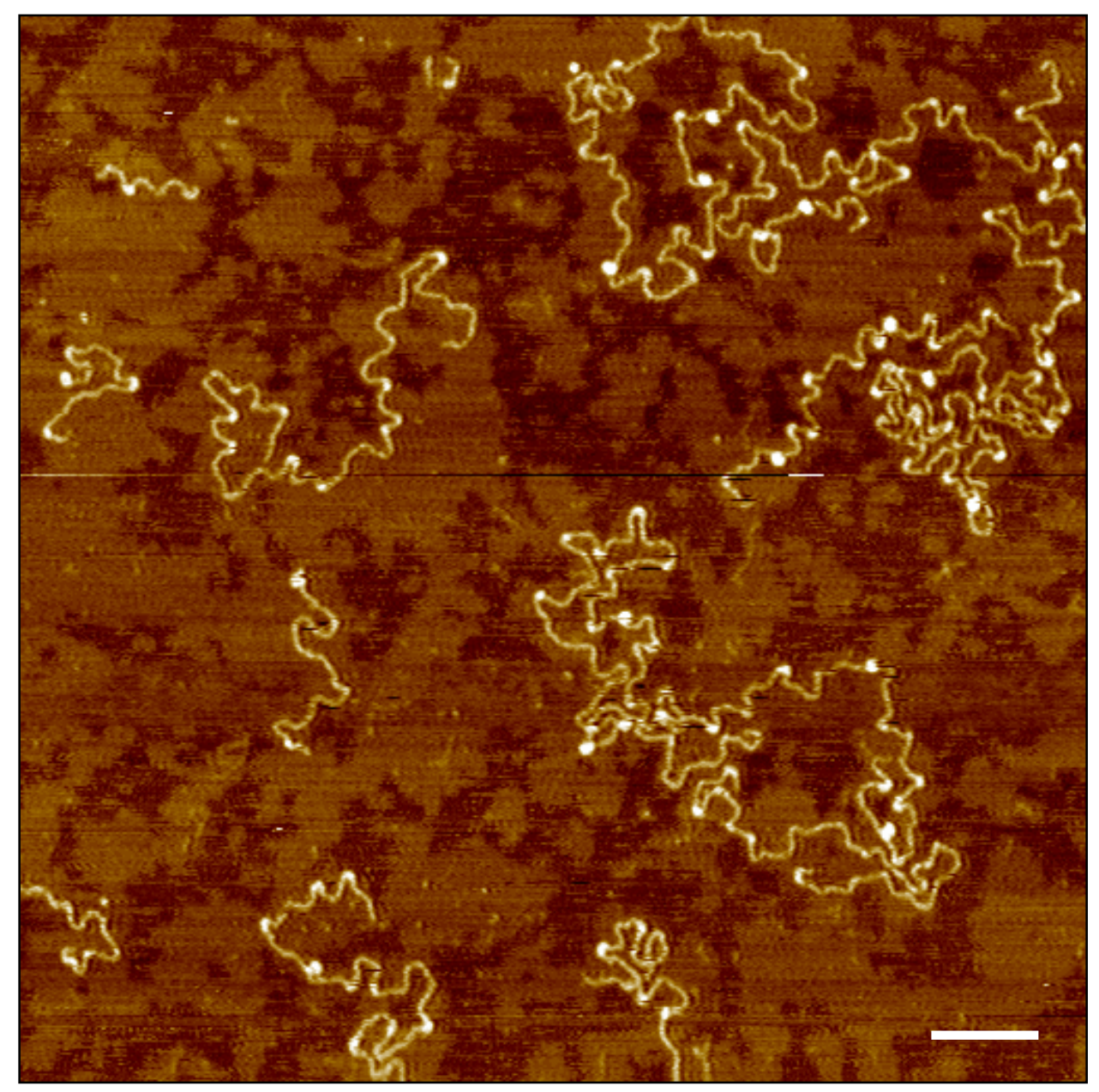

Figure 12. AFM of linker histone stripped CE chromatin on poly-L-lysine treated mica. Scale bar $100 \mathrm{~nm}$, height scale $0-5 \mathrm{~nm}$. 


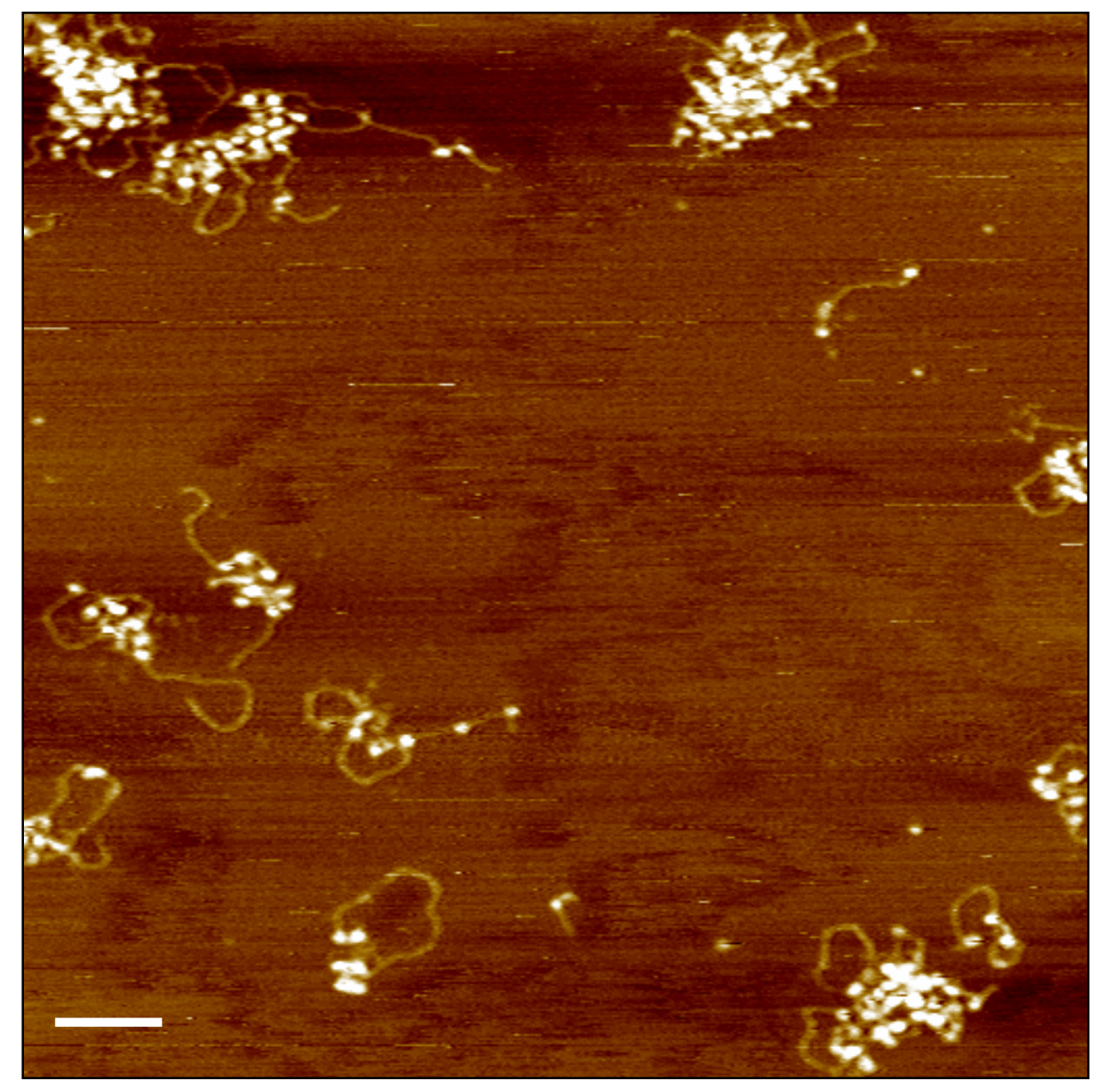

Figure 13. AFM of CE chromatin on plain mica. Scale bar $100 \mathrm{~nm}$, height scale 0-5 nm. 


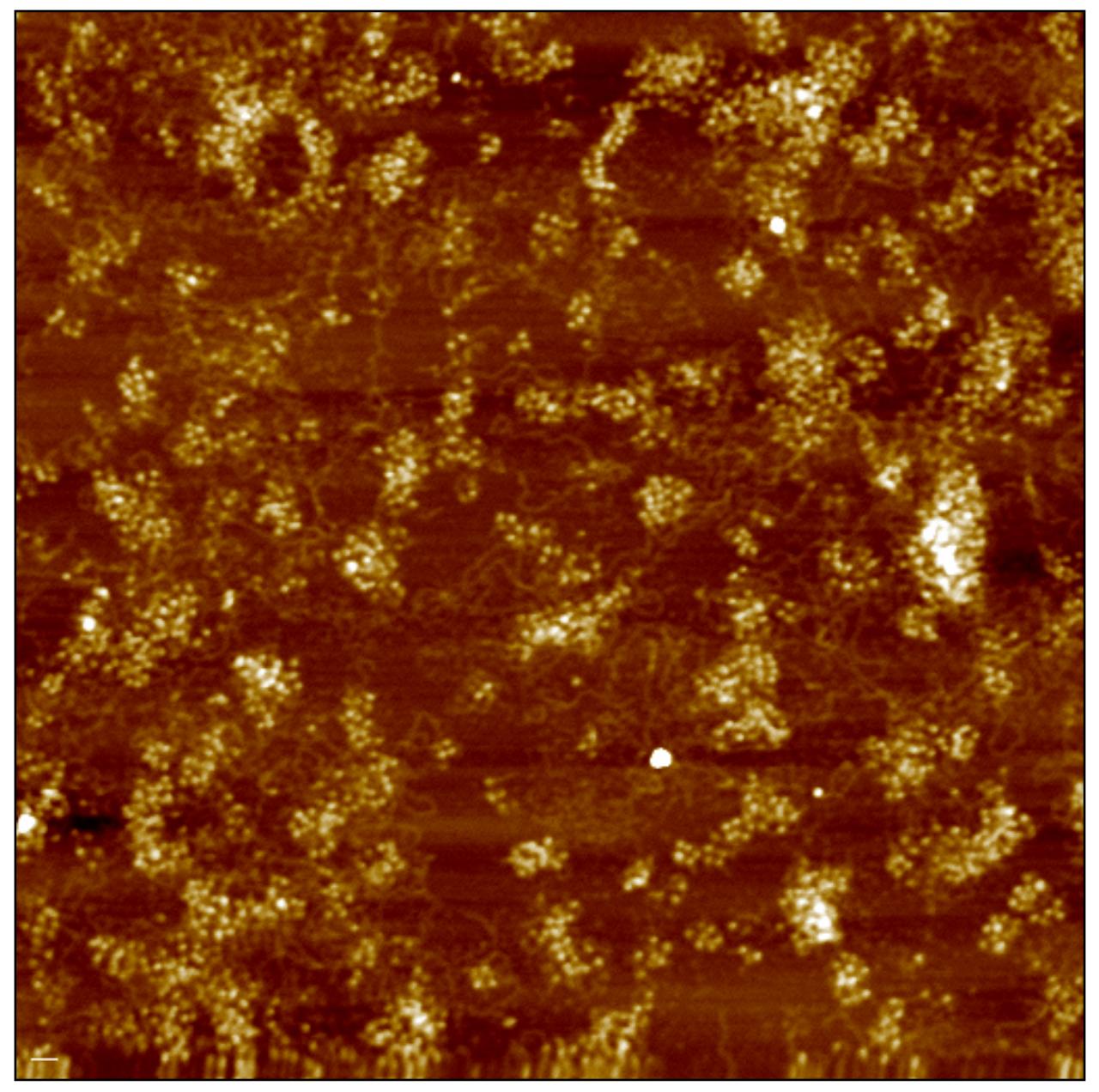

Figure 14. AFM of unfixed CE chromatin on plain mica. Scale bar $50 \mathrm{~nm}$, height scale 0$5 \mathrm{~nm}$. 


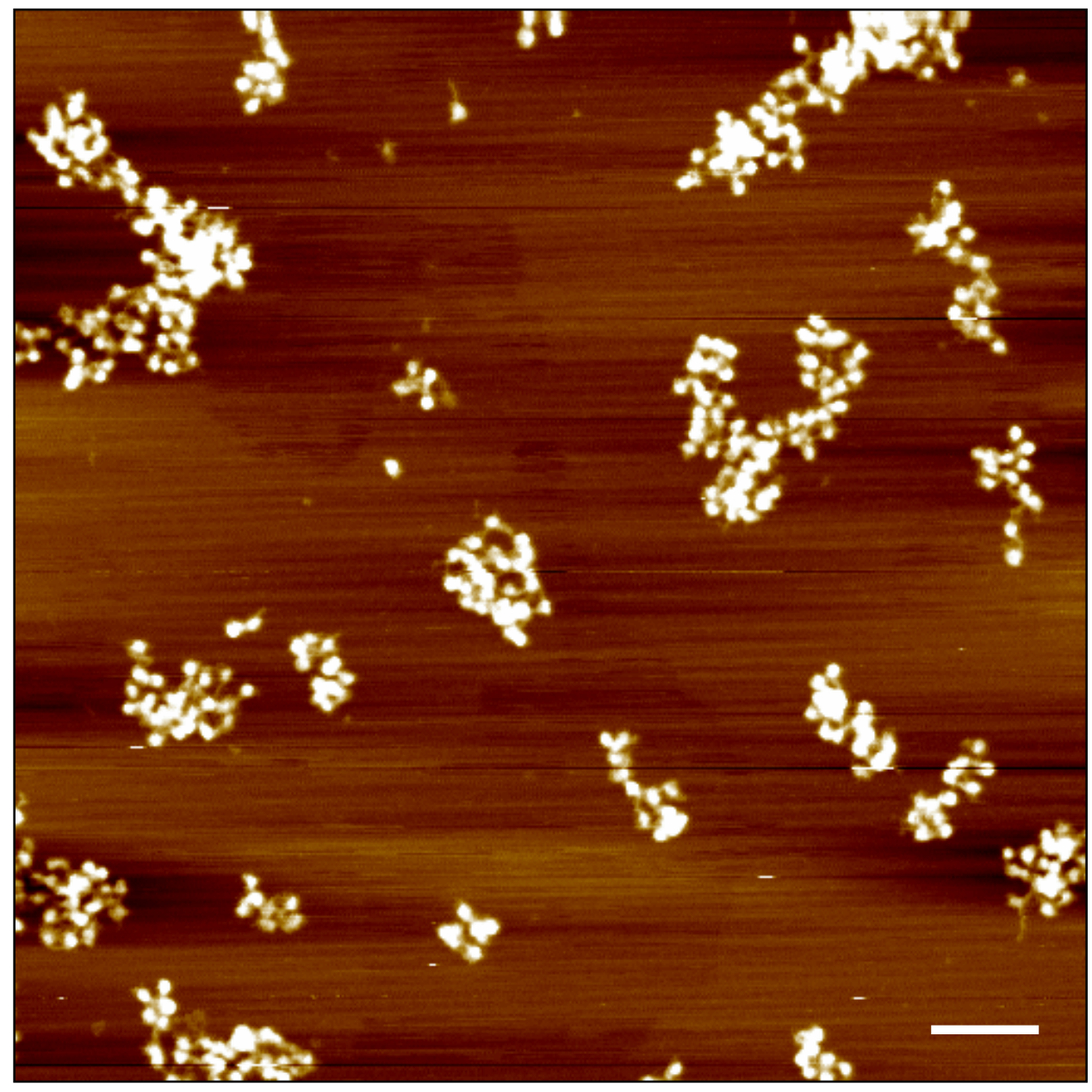

Figure 15. AFM of glutaraldehyde-fixed CE chromain on plain mica. Scale bar $100 \mathrm{~nm}$, height scale $0-5 \mathrm{~nm}$. 

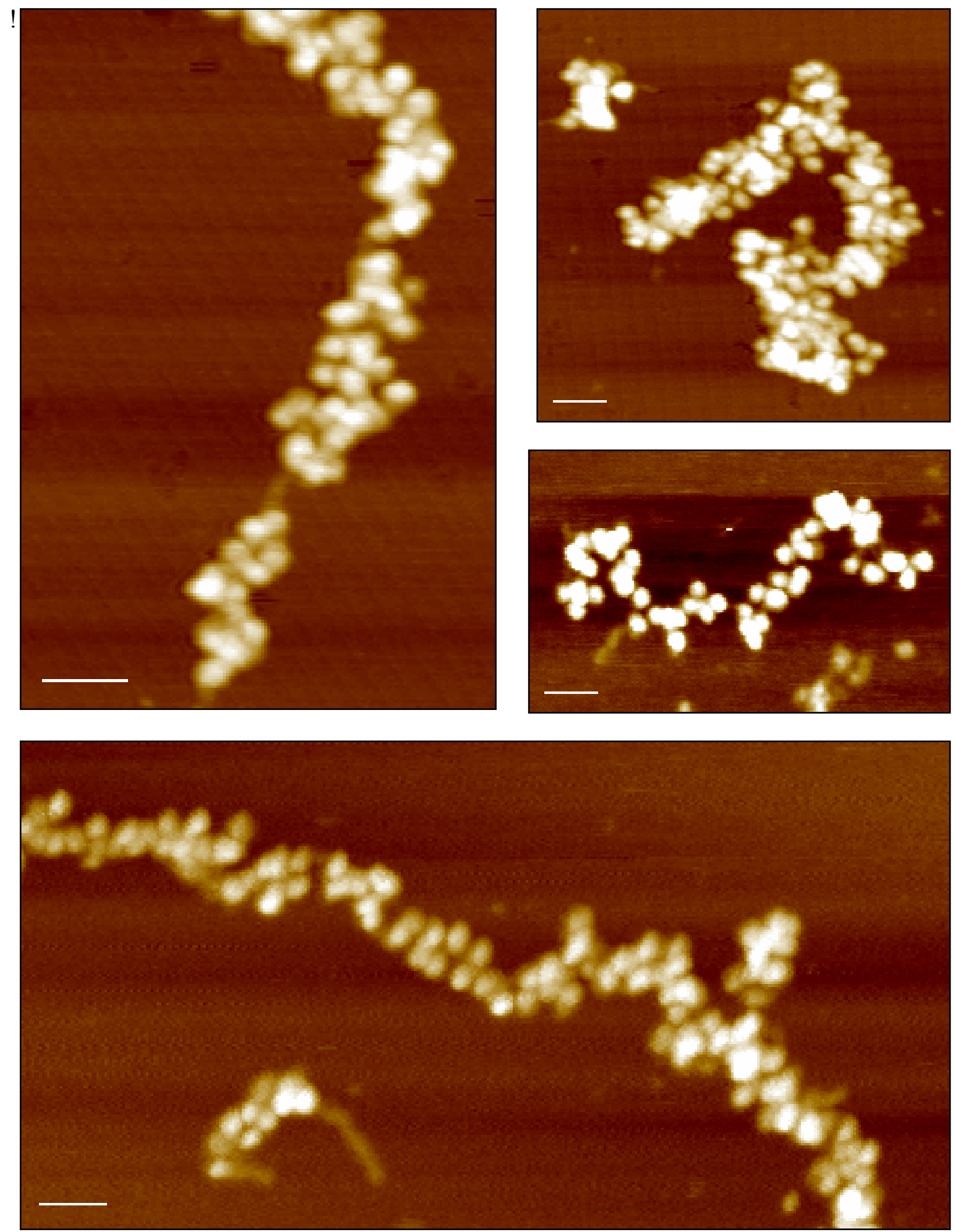

Figure 16. AFM of glutaraldehyde-fixed CE chromatin on plain mica. Scale bar $50 \mathrm{~nm}$, height scale $0-7 \mathrm{~nm}$. 

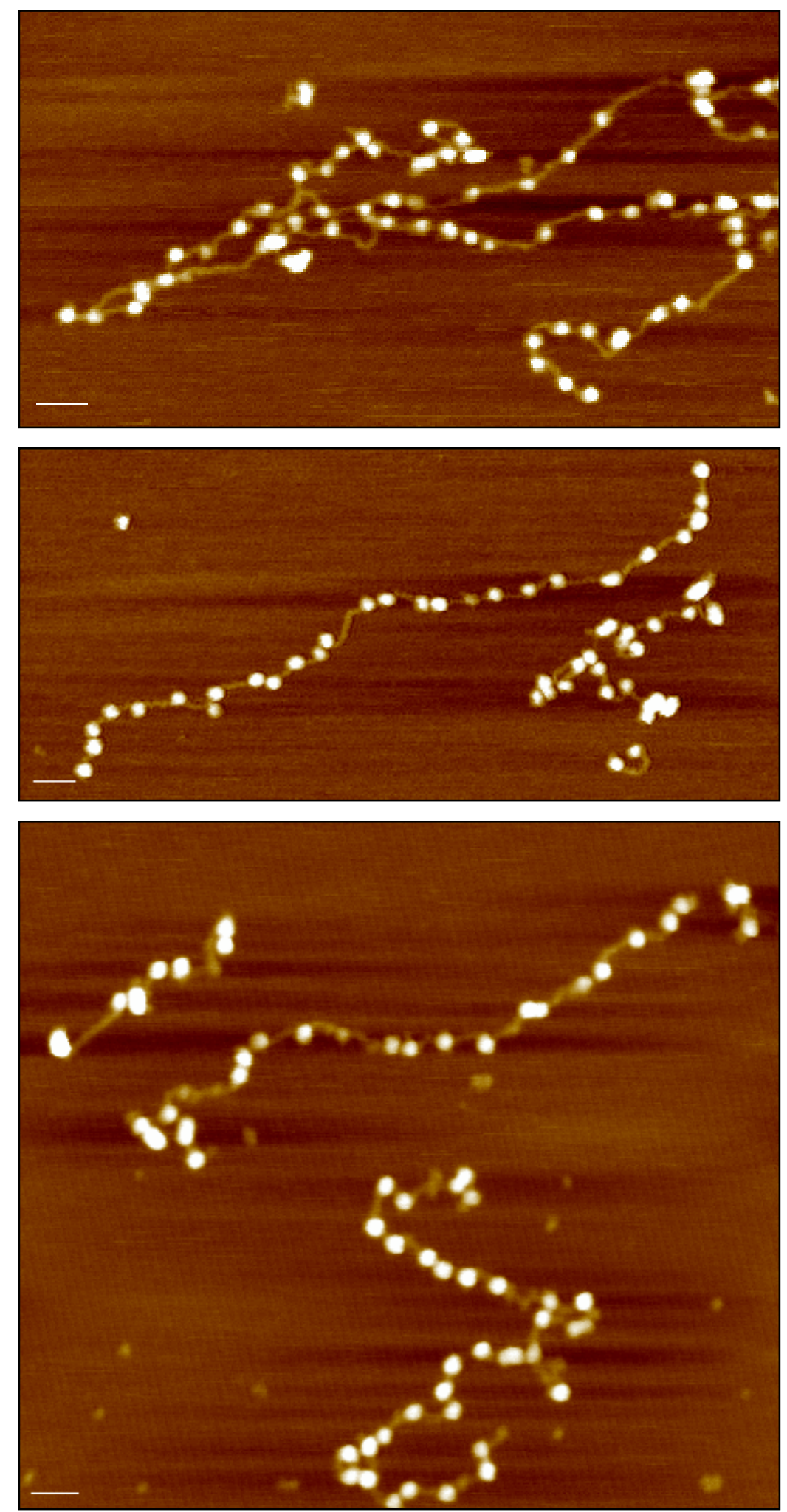

Figure 17. AFM of linker histone-stripped glutaraldehyde-fixed CE chromatin on untreated mica. Scale bar $50 \mathrm{~nm}$, height scale 0-5 nm. 

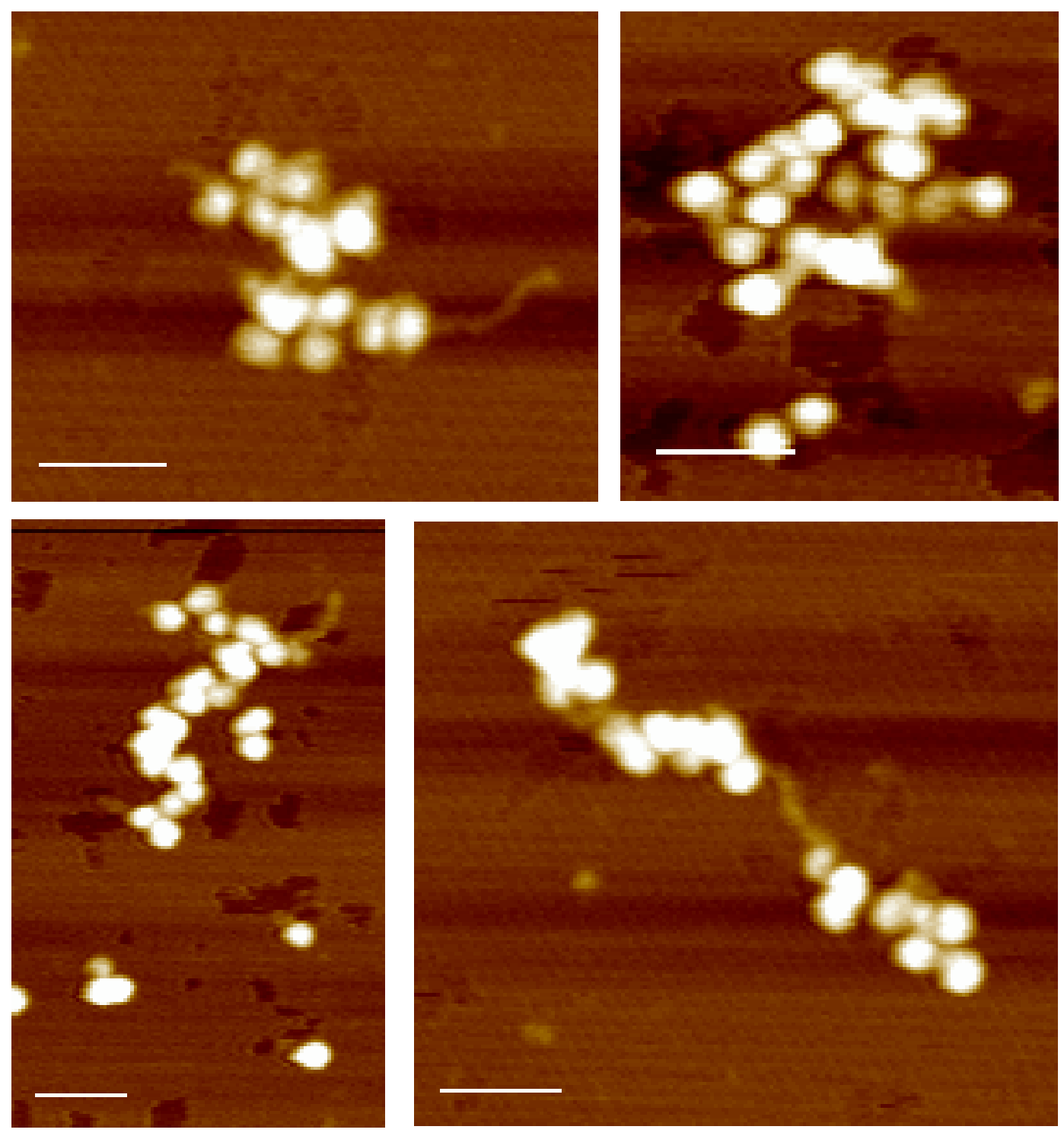

Figure 18. AFM of glutaraldehyde fixed $\mathrm{CHO}$ chromatin. Scale bars are $50 \mathrm{~nm}$. Height scale: 0-5 $\mathrm{nm}$. Images are representative of small chromatin fibers seen in samples from several preparations. 


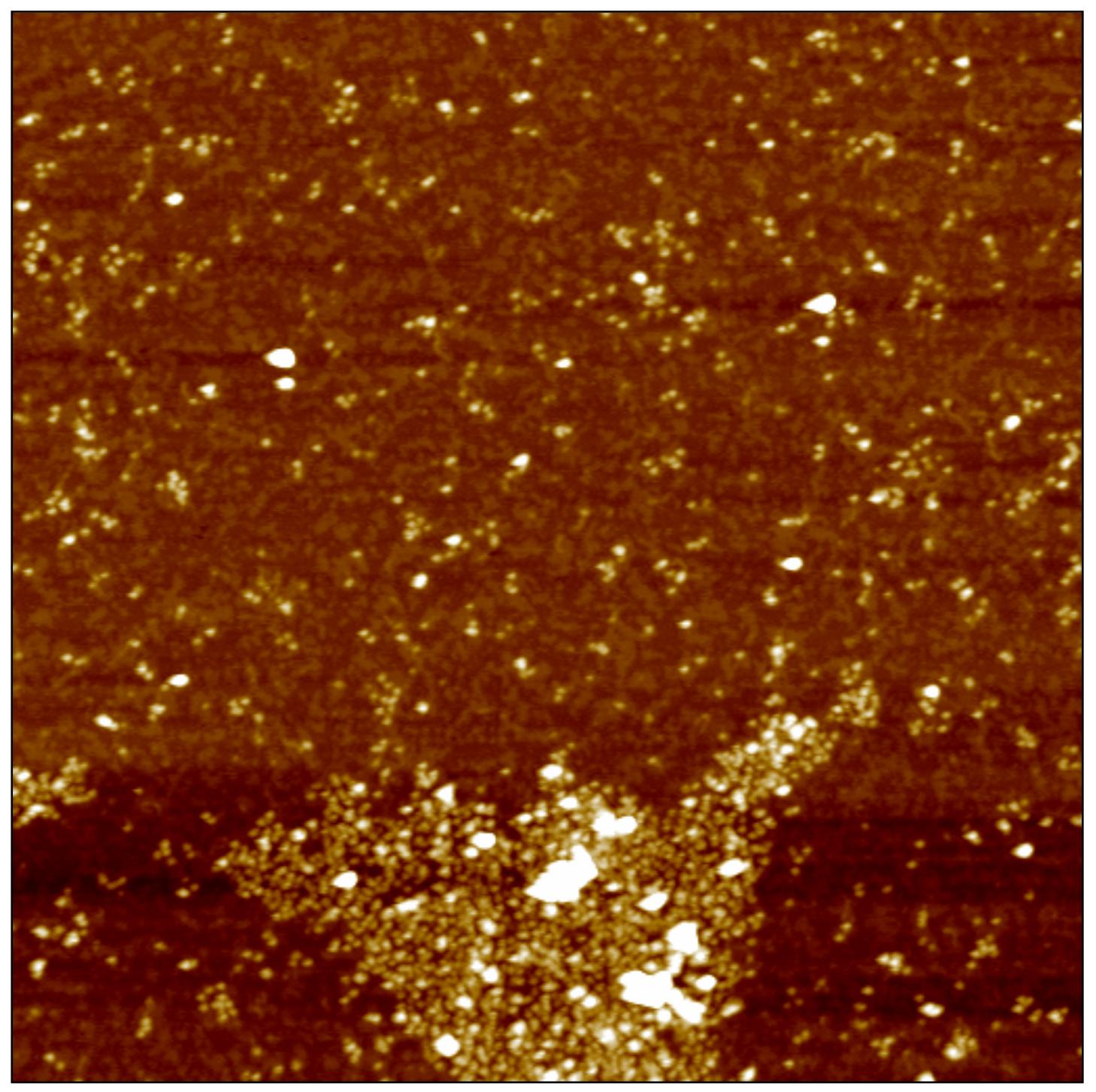

Figure 19. AFM image of glutaraldehyde fixed $\mathrm{CHO}$ chromatin. Image is $2 \mu \mathrm{m}$ square, height scale 0-5 nm. 

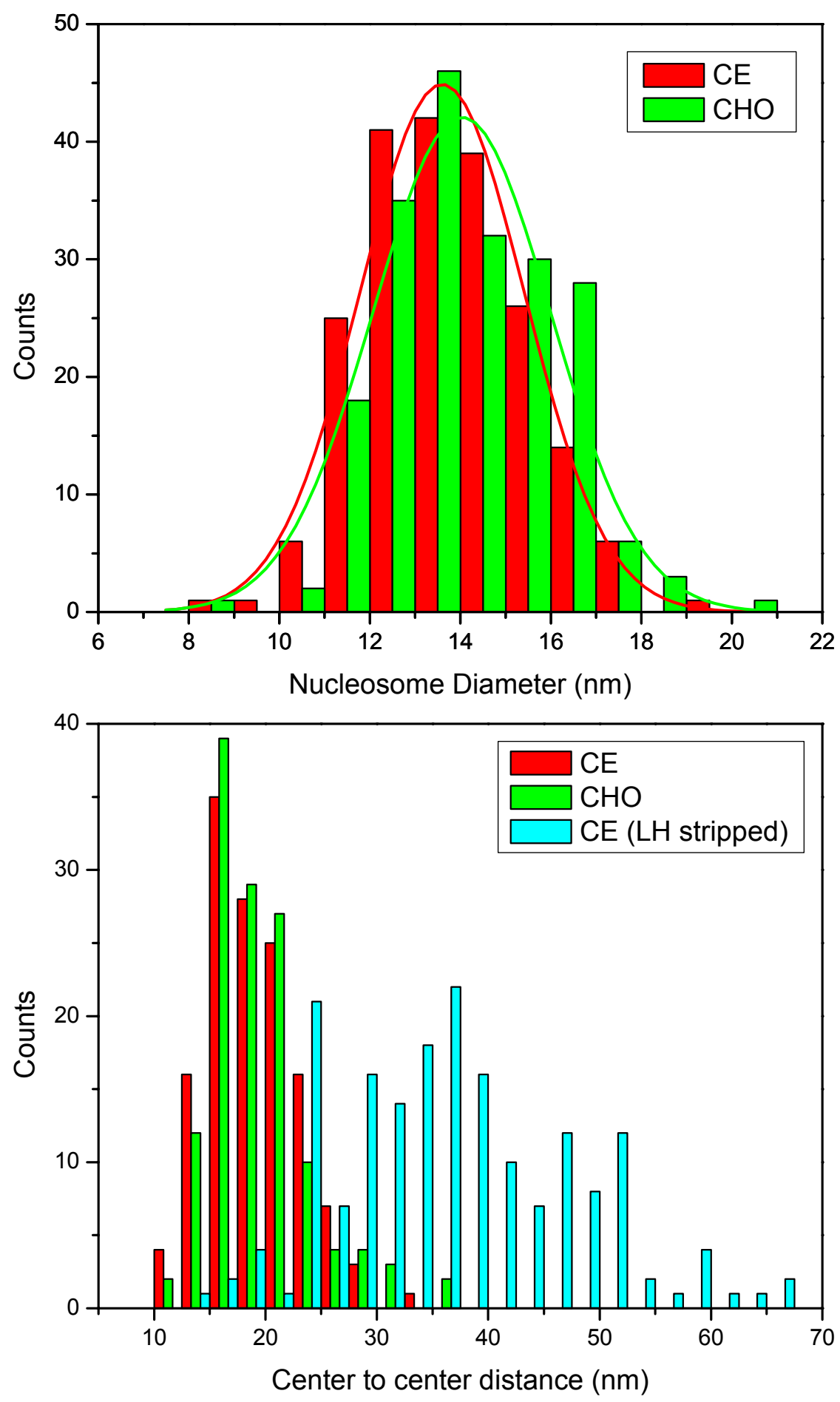

Figure 20. Histograms of nucleosome diameters and center-center distances for CE, linker histone-stripped CE (CE LH-stripped) and CHO chromatin. See text for details. 


\section{References}

Alberts, B., Johnson, A., Lewis, J., Raff, M., Roberts, K., and Walter, P. (2002).

Molecular Biology of the Cell, 4th edn (New York, Garland Science).

Bennink, M. L., Leuba, S. H., Leno, G. H., Zlatanova, J., Grooth, B. G. d., and Greve, J. (2001). Unfolding Individual Nucleosomes by Stretching Single Chromatin Fibers with Optical Tweezers. Nature Structural Biology 8, 606-610.

Brower-Toland, B., Wacker, D., Fulbright, R., Lis, J., Kraus, W., and Wang, M. (2005). Specific Contributions of Histone Tails and their Acetylation to the Mechanical Stability of Nucleosomes. Journal of Molecular Biology 346, 135-146.

Bustamante, C., Zuccherid, G., Leuba, S. H., Yanga, G., and Samori, B. (1997).

Visualization and Analysis of Chromatin by Scanning Force Microscopy. Methods 12, 73-83.

Carruthers, L., Tse, C., Walker, K., and JC, H. (1999). Assembly of Defined Nucleosomal and Chromatin Arrays from Pure Components. Methods in Enzymology 304, 19-35.

Cui, Y., and Bustamante, C. (2000). Pulling a Single Chromatin Fiber Reveals the Forces that Maintain its Higher-Order State. Proceedings of the National Academy of Sciences USA 97, 127-132.

D'Anna, J. A., Tobey, R. A., and Gurley, L. R. (1980). Concentration-Dependent Effects of Sodium Butyrate in Chinese Hamster Cells: Cell-Cycle Progression, Inner-Histone Acetylation, Histone H1 Dephosphorylation, and Induction of an H1-like Protein. Biochemistry 19, 2656-2671.

Davey, C. A., Sargent, D. F., Luger, K., Maeder, A. W., and Richmond, T. J. (2002). Solvent Mediated Interactions in the Structure of the Nucleosome Core Particle at $1.9 \AA$ Resolution. Journal of Molecular Biology 319, 1097-1113.

Dorigo, B., Schalch, T., Kulangara, A., Duda, S., Scroeder, R. R., and Richmond, T. J. (2004). Nucleosome Arrays Reveal the Two-Start Organization of the Chromatin Fiber. Science 306, 1571-1573.

Finch, J., and Klug, A. (1976). Solenoidal Model for Superstructure in Chromatin. Proceedings of the National Academy of Sciences USA 73, 1897-1901.

Fischle, W., Wang, Y., and Allis, C. D. (2003). Histone and Chromatin Cross-Talk. Current Opinion in Cell Biology 15, 172-183. 
Grewal, S. I. S., and Elgin, S. C. R. (2002). Heterochromatin: New Possibilities for the Inheritance of Structure. Current Opinion in Genetics and Development 12, 178-187.

Horn, P. J., and Peterson, C. L. (2002). Chromatin Higher Order Folding: Wrapping Up Transcription. Science 297, 1824-1827.

Kepert, J. F., Mazurkiewics, J., Heuvelman, G. L., Toth, K. F., and Rippe, K. (2005). NAP1 Modulated Binding of Linker Histone H1 to Chromatin and Induces an Extended Chromatin Fiber Conformation. Journal of Biological Chemistry 280, 34063-34072.

Leuba, S. H., Yang, G., Robert, C., Samori, B., Holde, K. v., Zlatanova, J., and Bustamante, C. (1994). Three-Dimensional Structure of Extended Chromatin Fibers as Revealed by Tapping-Mode Scanning Force Microscopy. Proceedings of the National Academy of Sciences USA 91, 11621-11625.

Leuba, S. H., Zlatanova, J., Karymov, M. A., Bash, R., Liu, Y.-Z., Lohr, D., Harrington, R. E., and Lindsay, S. M. (2000). The Mechanical Properties of Single Chromatin Fibers Under Tension. Single Molecule 1, 185-192.

Li, J., Bai, C., Wang, C., Zhu, C., Lin, Z., Li, Q., and Cao, E. (1998). A Convenient Method of Aligning Large DNA Molecules on Bare Mica Surfaces for Atomic Force Microscopy. Nucleic Acids Research 26, 4785-4786.

Luger, K., Mäder, A. W., Richmond, R. K., Sargent, D. F., and Richmond, T. J. (1997). Crystal structure of the nucleosome core particle at $2.8 \AA$ resolution. Nature 389, 251260.

Neely, K. E., and Workman, J. L. (2002). The Complexity of Chromatin Remodeling and its Links to Cancer. Biochimica et Biophysica Acta 1603, 19-29.

Peterson, C. L., and Workman, J. L. (2000). Promoter Targeting and Chromatin Remodeling by the SWI/SNF Complex. Current Opinion in Genetics and Development 10, 187-192.

Pollard, K. J., and Peterson, C. L. (1998). Chromatin Remodeling: a Marriage Between Two Families? Bioessays 20, 771-780.

Pope, L. H., Bennink, M. L., and Greve, J. (2002). Optical Tweezers Stretching of Chromatin. Journal of Muscle Research and Cell Motility 23, 397-407.

Schalch, T., Duda, S., Sargent, D. F., and Richmond, T. J. (2005). X-ray Structure of a Tetranucleosome and its Implications for the Chromatin Fiber. Nature 436, 138-141.

Shore, D. (2001). Telomeric Chromatin: Replicating and Wrapping Up Chromosome Ends. Current Opinion in Genetics and Development 11, 189-198. 
Strahl, B. D., and Allis, C. D. (2000). The Language of Covalent Histone Modifications. Nature 403, 41-45.

Thoma, F., Koller, T., and Klug, A. (1979). Involvement of Histone H1 in the Organization of the Nucleosome and the Salt-Dependent Superstructures of Chromatin. Journal of Cell Biology 83, 402-427.

Vignali, M., Hassan, A. H., Neely, K. E., and Workman, J. L. (2000). ATP-Dependent Chromatin-Remodeling Complexes. Molecular and Cellular Biology 20, 1899-1910.

von Holt, C., Brandt, W., Greyling, H., Lindsey, G., Retief, J., Rodrigues, J. d. A., Schwager, S., and Sewell, B. (1989). Isolation and Characterization of Histones. Methods in Enzymology 170, 431-523.

Wolffe, A. (1998). Chromatin: Structure and Function, 3rd edn (San Diego, Academic Press).

Woodcock, C., Frado, L., and Rattner, J. (1984). The Higher Order Structure of Chromatin: Evidence for a Helical Ribbon Arrangement. Journal of Cell Biology 99, 4252.

Yager, T. D., McMurray, C. T., and Holde, K. E. v. (1989). Salt-Induced Release of DNA from Nucleosome Core Particles. Biochemistry 28, 2271-2281.

Zlatanova, J., Leuba, S. H., Yang, G., Bustamante, C., and Holde, K. v. (1994). Linker DNA Accessibility in Chromatin Fibers of Different Conformations: A Reevaluation. Proceedings of the National Academy of Sciences USA 91, 5277-5280.

Zlatanova, J., Lindsay, S. M., and Leuba, S. H. (2000). Single Molecule Force Spectroscopy in Biology Using the Atomic Force Microscope. Progress in Biophysics and Molecular Biology 74, 37-61. 